\title{
Aggregate Production Planning for Process Industries under Oligopolistic Competition
}

\author{
Uday S. Karmarkar \\ Kumar Rajaram \\ UCLA Anderson School of Management \\ 110 Westwood Plaza, \\ Los Angeles, CA 90095
}

July 5, 2012

\begin{abstract}
$\underline{\text { Abstract }}$
We consider a competitive version of the traditional aggregate production planning model with capacity constraints. In the general case, multiple products are produced by a few competing producers (oligopoly) with limited capacities. Production quantities, prices and consequently profits depend on production and allocation decisions of each producer. In addition, there is competition for the raw material whose supplies are limited, and where prices reflect these limitations. Such situations have recently occurred in several process industry settings including petro-refining, petrochemicals, basic chemicals, cement, fertilizers, pharmaceuticals, rubber, paper, food processing and metals. We use a successive "Bertrand-Cournot" framework to address this problem and to determine optimal production quantities, prices and profits at the producers and at the raw material supplier. Our analysis allows a new way to understand and evaluate the marginal value of additional capacity when there is competition for the market and raw materials.
\end{abstract}

\section{INTRODUCTION}

Traditional aggregate production planning models are usually cast in terms of allocating scarce resources and capacity to competing products (Hax, 1978). They are most commonly formulated as linear programs that minimize costs for a single producer, with products, demand levels and prices given. However, in many process industries, competition, capacity constraints, and competition for raw material supply often cause significant market effects so that production and allocation decisions themselves affect price and profit. These situations occur frequently in sectors that produce high volume, commodity products for which capacity is expensive and not easily expanded. In addition, long planning horizons, raw material shortages and modest rates of return on investments leave producers with little incentive to add capacity or to carry excess capacity. Examples can be found across a variety of process industry sectors such as petro-refining, petrochemicals, basic chemicals, cement, fertilizers, pharmaceuticals, rubber, paper, food processing and metals. In some cases, such as the oil refining and steel industries, there are interactions 
between capacity constraints, shifts in demand curves and raw material availability (e.g., crude in oilrefining and scrap metal in steel).

Traditional aggregate production planning models are applicable in a stable economic environment, with low rates of change. Consequently, factories can operate in a relatively stable manner, with capacity and mix changes being made infrequently. However, in the last decade, we have seen rapid changes in many process industry sectors usually brought about by competition within the sector and by economic growth in emerging economies, with the consequent increases in demand. In such situations, raw material availability and processing capacity can both be significant constraints. Here, the traditional aggregate production planning formulations are not able to capture the competition in the production tier for the raw material, nor the competitive interactions between producers on variables such as production quantities, capacity constraints, raw material availability and price. Consequently, it is doubtful whether product mix and market allocation decisions made using a single-producer cost minimization model could correctly reflect the interactions between decisions of competitors and the response of markets and prices to production quantities. Indeed, we will show that concepts such as Lagrange multipliers, reflecting the marginal value of capacity, can be subject to misinterpretation to the point of being misleading.

In this paper, we formulate a competitive version of the traditional aggregate production planning model with capacity constraints. We utilize a successive Bertrand-Cournot framework in which the raw material supplier sets the price (i.e. the Bertrand model) and the producer then sets the production quantity (i.e. the Cournot model). As we will discuss, this framework is very useful in incorporating the interactions with the raw material supplying sector where supplies are limited, and where prices reflect these limitations. We first use small examples to provide explicit solutions that provide insight; larger problems require numerical solution methods. We show that it is possible to have a situation in which capacity is fully utilized, but for which the multiplier on capacity is zero and, yet, the value of a marginal expansion of capacity can still be positive. Here, Lagrange multipliers can have a very different interpretation then the traditional one of marginal value for increases in a constrained resource. In addition, we show that the multiplier does not capture the additional value of capacity for the producer due to competitive interactions between producers for the raw material used. We next develop a computational method to solve larger problems and test this method on an illustrative example. This analysis also provides insight into the impact of production efficiencies (i.e., supplier's and producers' unit production costs) and market parameters (i.e., market size and customer price sensitivity) on prices, production quantities and profits for both the supplier and the producers' tiers.

This paper is organized as follows. In the next section, we review the relevant literature. In Section 3, we formulate our model. In Section 4, we examine the special case of a single product, single raw material with a monopolistic supplier. In this context, we consider both homogenous and heterogeneous 
producers. In Section 5, we develop a computational method to solve general versions of this problem with multiple producers, products and raw materials. We test this method on an illustrative example. In the concluding section, we summarize the major results of the paper and suggest future research directions.

\section{LITERATURE REVIEW}

There is substantial literature on aggregate production planning decisions that address production mix, capacity allocation, seasonal inventory planning and distribution planning with annual planning horizons. Early formulations of employed linear programming (Hanssmann and Hess, 1960) and quadratic cost models (Holt, Modigliani et al., 1960) to represent the problem. Extensions of the linear programming model included its use in hierarchical control schemes, sometimes through column generation techniques (Lasdon and Terjung, 1971). Such models correspond to annual budgeting and sales planning cycles, and usually serve the purpose of inter-functional coordination. Recent surveys are presented by Nam and Logendran (1992), Dauzere-Peres and Lasserre (1994), and Pochey and Wolsely (2006). Specific applications to the process industry can be found in Dutta and Fourer (2004) and Dutta et al. (2007). However, none of this work captures the relationship between production quantities and prices, and the interactions between capacity constraints, shifts in demand curves and the raw material supply tier.

Models of Cournot competition have a long history going back to the original paper by Cournot (1838). There are several streams of research that address multi-tier competition. Machlup and Taber (1960) provide an early overview of successive monopoly in two tiers. Much of the literature since has addressed vertical integration and competitiveness. Greenhut and Ohta (1979) show that vertical integration of successive oligopolists leads to higher output and lower prices. Abiru (1988) extends this to a wider range of cases. Ziss (1995) studies horizontal mergers in two-tier supply chains with two entrants at each tier, two part pricing and the lower tier faces linear demand. They then show that upstream merger leads to higher final prices due to higher supply prices resulting from the monopoly at the upper tier. On the other hand, if the monopoly is formed by merger at the lower tier, the two entrants at the upper tier compete and reduce supply prices to such an extent final process are reduced. The successive Cournot model is extended to an arbitrary number of serial tiers, by Corbett and Karmarkar (2001) who also consider entry and vertical integration. There are other substantial streams of literature addressing topics like vertical restraints, vertical relationships and channel coordination. Bernstein and Federgruen (2005) study distribution systems with competing retailers, considering discounts and more general contracting schemes. Carr and Karmarkar (2005) consider large assembly networks along with the vertical and lateral effects of entry. Bernstein and DeCroix (2005) study the effect of outsourced sub-assembly in assembly 
systems. None of these above papers consider multi-product production planning with capacity constraints.

The literature on capacity constrained competition is quite limited. Moreover, managerial issues are rarely addressed in this literature. Haskell and Martin (1994) examine the behavior of capacity constrained producers, and conclude that they exhibit Cournot-like behavior. Herk (1993) formulates a two-stage duopoly model with capacity choice followed by price competition and shows that capacity choices exhibit Cournot behavior. Of the papers that are similar to the setting of our work are Karmarkar and Pitbladdo $(1993,1994)$ who study a two-stage, single-tier formulation with entry at the first stage and multi-product Cournot competition with capacity constraints at the second stage. Our work differs from theirs in that we focus on the tactical (second stage) problem with fixed (given) capacity, permit heterogeneity of producers and consider multiple products, multiple capacity constraints and interactions with the raw material supply tier.

Previous work that is closest to our model is that of Zappe and Horowitz (1993) who examine a multi-product, multi-market model and study the effect of capacity on competitive response under quasiCournot conjectures. In addition, they embed a capacity decision into the Cournot quantity decision. As a consequence, they limit their analysis to a problem with two identical producers, one product, two capacity levels and two markets, and restrict their investigation to the symmetric case. Further, they do not consider the two-tier case that includes the raw material supplier. In contrast, our emphasis is on developing methods to analyze planning decisions in a multi-tier setting consisting of producers and the raw material supplier.

This paper extends the traditional aggregate planning model to include the case when there are a few competing producers (oligopoly) who produce multiple products under capacity constraints. The production quantity of each product across all producers determines the price and eventually profits. Further, there is competition in the production tier for the raw materials. Such situations have most recently been observed in the petro-refining (Coy, 2004) and copper processing sectors (Morrison, 2005). To the best of our knowledge, this is the first paper in the literature to consider this problem. In this context, this paper makes the following contributions:

1) We develop methods to address large-sized real problems efficiently. Our methods explicitly calculate prices and production quantities at the producers and raw material supplier level and show how they can be different from the traditional aggregate production planning model without competition. This is important to researchers and practitioners as if we ignore competitive effects the results are misleading and could lead to the wrong production planning quantities. Our results are relevant across several process industry sectors such as petro-refining and metals processing. 
2) Our methods develop managerial insight by developing a new way to understand and evaluate the marginal value of additional capacity when there is competition for the market and raw materials. This new understanding of the marginal value of capacity expansion is very important to make the correct production planning and capacity expansion decisions to succeed in a competitive environment with restrictions on raw material availability.

3) We conduct extensive numerical analysis based on a realistic example and provide managerial insight on how market parameters and production efficiencies affect price, production quantity and profitability at the supplier and the producer's tier.

\section{MODEL FORMULATION}

Consider $m$ producers indexed by $i \in(1,2, \ldots m)$ producing $n$ commodity products indexed by $j \in(1,2$, .. n). Let variable $q_{i j}$ represent the production quantity for product $j$ at producer $i$ and $Q_{j}=\sum_{i=1}^{m} q_{i j}$ denote the total amount of product $j$ available in the market. For example, in the context of the petrochemical industry, these producers can be considered as the refiners of crude oil (e.g. Shell, Exxon Mobil, Chevron, etc.), while products could be the different grades of gasoline (e.g. Regular, Plus and Supreme). We assume that demand for product $j$ is characterized by an affine inverse demand function $p_{j}$ $=a_{j}-b_{j} Q_{j}$, where $p_{j}$ is the price for product $j$, while $a_{j}$ and $b_{j}$ are parameters. Here, $a_{j} / b_{j}$ can be considered as the market size and $1 / b_{j}$ can be regarded as the customer price sensitivity. This can also be viewed as an affine approximation of the actual demand function and has been commonly used in the literature (Karmarkar and Pitbladdo, 1993; Corbett and Karmarkar, 2001). We are given:

$v_{i j}$ : production cost per unit of product $j$ at producer $i$ (\$/unit),

$c_{i j}$ : capacity required per unit of product $j$ at producer $i$ (capacity units/unit), and

$d_{i}$ : total capacity available at producer $i$.

We assume quantity competition at the producers to model production planning decisions under competition, as price competition with more than one producer will lead to marginal cost pricing. If raw material prices are assumed to be exogenous, we can plausibly utilize a Cournot framework in which producers make decisions on production quantities by allocating capacity across products and by choosing how to allocate production across markets. Given a demand curve, this establishes product prices. However, in process industry setting, it is unrealistic to assume raw material prices are exogenous. This is because there are interactions with the raw material supplying sector, where supplies are limited, and where raw material prices reflect these limitations. This situation occurs in oil production, where the supply of crude is often controlled by a group of countries such as the OPEC (Griffin, 1985). It also 
occurs in a number of other industries, for which the item in limited supply could be a raw material commodity like copper, a rare material like uncut diamonds or a manufactured product like DRAM chips.

To include interactions with the raw material supply tier, we consider a monopolist price setting supplier and consider $r$ raw materials indexed by $k \varepsilon(1,2, \ldots r)$. Further, let $p^{k}$ represent the price of these raw materials, $v^{k}$ represent production costs per unit of the raw material and $r_{i j k}$ be a consumption factor representing the number of units of raw material consumed for the production of a unit of product $j$ at producer $i$. We model the interaction between the raw material supplier and the producers using a successive "Bertrand-Cournot" framework. In this framework, the supplier sets raw material prices to maximize profits subject to capacity constraints on raw material production. At this price, the raw material production quantity equals the total requirements across all producers. Given these raw material prices, the producers solve the Cournot game to determine the optimal production quantities by allocating capacity across a set of products. Given a demand curve for the product, this establishes prices for the end customer. The successive "Bertrand-Cournot” framework is similar in concept to the successive Cournot framework commonly used in the literature (Machlup and Taber, 1960; Greenhut and Ohta, 1979; Abiru, 1988; Corbett and Karmarkar, 2001). However the successive Cournot framework cannot be always employed in our context, as in general, the raw material demand function may not be invertible.

Using the successive "Bertrand-Cournot” framework, producer $i$ considers the following problem:

$$
\Pi_{i}=\operatorname{Max} \sum_{j=1}^{n}\left\{\left(p_{j}-\left(v_{i j}+\sum_{k=1}^{r} p^{k} r_{i j k}\right)\right) q_{i j}\right\}
$$

Subject to:

$$
\begin{aligned}
& \sum_{j=1}^{n} c_{i j} q_{i j} \leq d_{i}, \\
& q_{i j} \geq 0, \quad \forall j .
\end{aligned}
$$

Objective function (1) maximizes profits at producer $i$ by choosing the appropriate production quantity, $q_{i j}$, given the production quantities at the other producers (i.e., $q_{p j}, \forall p \neq i$ ). Constraint (2) ensures capacity limits at producer $i$, while non-negativity constraints are enforced by (3).

When raw material prices $p^{k}, \forall k$ is set by the supplier, then the equilibrium production quantities and prices at the producers can be easily found. Here we substitute $p_{j}=\left(a_{j}-b_{j} \sum_{i=1}^{m} q_{i j}\right)$ in (1) and note that (P1) is a concave optimization problem. We then relax constraint (2) by introducing Lagrange multiplier $\lambda_{i}$ to get the following dual problem for the $i^{\text {th }}$ producer: 


$$
\Pi_{i}^{D}=\underset{q_{i j} \geq 0, \lambda_{i} \geq 0}{\operatorname{Max}} \sum_{j=1}^{n}\left\{\left(a_{j}-b_{j} \sum_{i=1}^{m} q_{i j}-\left(v_{i j}+\sum_{k=1}^{r} p^{k} r_{i j k}\right)-\lambda_{i} c_{i j}\right) q_{i j}\right\}+\lambda_{i} d_{i}
$$

From (4), the sufficient first order conditions with respect to $q_{i j}$ can be found by setting $\frac{\partial \Pi_{i}^{D}}{\partial q_{i j}}=0$, so that:

$$
2 q_{i j}+\sum_{t \neq i} q_{t j}=\frac{a_{j}-\left(v_{i j}+\sum_{k=1}^{r} p^{k} r_{i j k}\right)-\lambda_{i} c_{i j}}{b_{j}}, \forall i, j .
$$

Proposition 1: There exists a unique vector of equilibrium order quantities $q_{i j}^{*}, \forall i, j$.

Proof. All Proofs are provided in the supplemental online appendix.

In light of Proposition 1, we can find the equilibrium production quantities $q_{i j}^{*}, \forall i, j$, by solving the system of equations defined in (5) to get:

$$
q_{i j}^{*}=\frac{\left\{a_{j}-m\left(v_{i j}+\sum_{k=1}^{r} p^{k} r_{i j k}+\lambda_{i} c_{i j}\right)+\sum_{t \neq i}\left(v_{t j}+\sum_{k=1}^{r} p^{k} r_{t j k}+\lambda_{t} c_{t j}\right)\right\}}{(m+1) b_{j}} \quad \forall i, j .
$$

The total quantity $q_{j}^{*}$ of product $j$ in the market is given by:

$q_{j}^{*}=\sum_{i} q_{i j}^{*}=\frac{m a_{j}}{(m+1) b_{j}}+\frac{\sum_{i}\left\{\sum_{t \neq i}\left(v_{t j}++\sum_{k=1}^{r} p^{k} r_{t j k}+\lambda_{t} c_{t j}\right)-m\left(v_{i j}+\sum_{k=1}^{r} p^{k} r_{i j k}+\lambda_{i} c_{i j}\right)\right\}}{(m+1) b_{j}}$.

As expected, it can be observed from (6) and (7) that for a given $j, q_{i j}^{*}$ and $q_{j}^{*}$ increase when market size increases, and when production costs, capacity requirements and costs of capacity expansion increase for competing producers (i.e. $\forall t, t \neq i)$. On the other hand, $q_{i j}^{*}$ and $q_{j}^{*}$ decrease when the number of competing producers increase, and when capacity requirements, costs of capacity expansion and production costs increase at producer $i$. The equilibrium price $p_{j}^{*}$ for product $j$ is given by:

$$
p_{j}^{*}=a_{j}-b_{j} \sum_{i} q_{i j}^{*}=\frac{a_{j}-\sum_{i}\left\{\sum_{t \neq i}\left(v_{t j}+\sum_{k=1}^{r} p^{k} r_{t j k}+\lambda_{t} c_{t j}\right)-m\left(v_{i j}+\sum_{k=1}^{r} p^{k} r_{i j k}+\lambda_{i} c_{i j}\right)\right\}}{(m+1)} . \forall j
$$


It can be seen from (8) that the equilibrium price increases as market size increases, but decreases as the number of producers increases. To find the marginal value of capacity expansion under the equilibrium production quantities, we can use (5) to find $\lambda_{i}$, the Lagrange multiplier corresponding to producer $i$ as:

$\lambda_{i}=\frac{a_{j}-\left(v_{i j}+\sum_{k=1}^{r} p^{k} r_{i j k}\right)-b_{j}\left(2 q_{i j}^{*}+\sum_{t \neq i} q_{t j}^{*}\right)}{c_{i j}}$.

This shows that for a given producer, the Lagrange multiplier representing the marginal value of capacity expansion is increasing with market size for the product, but decreasing with production costs and production quantities at this producer. In addition, observe that the marginal value of capacity expansion at any producer is reduced by the total equilibrium production quantities produced by the competitors. This effect is not captured by the traditional, non-competitive Lagrange multiplier.

Next, we compare the marginal value of capacity expansion and the equilibrium production quantities and prices with the Non Competitive (NC) or monopolistic case. To perform this analysis, we set $i=$ (NC), $m=1$ in (6) and (8) to get the production quantities and prices in this case as:

$$
\begin{aligned}
& q_{(N C) j}^{*}=\frac{a_{j}-v_{(N C) j}+\sum_{k=1}^{r} p^{k} r_{(N C) j k}-\lambda(N C)^{C}(N C) j}{2 b_{j}} \\
& p_{(N C) j}^{*}=\frac{a_{j}+v_{(N C) j}+\sum_{k=1}^{r} p^{k} r_{(N C) j k}+\lambda_{(N C)}{ }^{C}(N C) j}{2}
\end{aligned}
$$

Proposition 2. When the capacity constraint is not binding and when production costs are equal across all producers, the monopolist produces less of the product at a higher price.

Our analysis thus far considers any raw material prices $p^{k}, \forall k$ set by the supplier. However, finding the optimal $p^{k}$ is intricate and requires constructing the demand function $Q^{k}\left(p^{k}\right)$ for each raw material $k$, and then solving the supplier's problem:

$$
\Pi^{o}=\operatorname{Max} \sum_{k=1}^{r}\left\{\left(p^{k}-v^{k}\right) Q^{k}\left(p^{k}\right)\right\}
$$

Subject to:

$$
\sum_{k=1}^{r} c^{k} Q^{k}\left(p^{k}\right) \leq d^{o}
$$




$$
p^{k} \geq 0
$$

Here, $c^{k}$ is the capacity required to produce one unit of raw material $k$ and $d^{0}$ is the total units of capacity available at the supplier. To solve (P2), we first need to construct $Q^{k}\left(p^{k}\right), \forall k$. To develop this function, let $Q^{k}=\sum_{i=1}^{m} \sum_{j=1}^{n} r_{i j k} q_{i j}$ represent the total amount of raw material $k$ required across all producers. We can use (6) in $Q^{k}=\sum_{i=1}^{m} \sum_{j=1}^{n} r_{i j k} q_{i j}$ to construct $Q^{k}\left(p^{k}\right)$. We can then substitute function $Q^{k}\left(p^{k}\right)$ into (12) and (13) and solve (P2) to find the optimal raw material prices. The equilibrium producer's quantities and prices can be calculated by using these optimal raw material prices and employing (6) through (8) along with the condition $\sum_{j=1}^{n} c_{i j} q_{i j}^{*}=d_{i}, \forall i$. In Section 5, we develop an efficient method to execute this procedure for large real problems. We next consider smaller versions of this problem to develop insight into how prices, production quantities and capacity constraints interact across the production and supply tiers.

\section{SPECIAL CASES}

There are some very significant strategic interactions that occur between the raw material supplier tier and the product processing tier. Some of these interactions are best revealed by examining simplified versions of the problem. As a start, we consider the problem in which there are multiple producers making a single product with a capacity constraint, and in which there is a single raw material supplied by a monopolist supplier. This setting allows us to derive insights into the relationship between capacity constraints and supply decisions and into the interpretation of Lagrange multipliers in a multi-tier competitive setting.

In the context of this simplified problem, we are able to demonstrate that, when all producers are homogenous with respect to capacity limits, there are systematic situations for which the Lagrange multipliers for the capacity constraints are zero, but a marginal increase in capacity can result in positive benefits for the producers. In short, the usual interpretation of Lagrange multipliers is not valid. We further show that when producers are heterogeneous and have varying capacity constraints, the Lagrange multipliers are generally not zero, but, again, their interpretation requires care. We show that in the latter case there is a critical marginal producer, whose capacity constraint has a significant effect on the entire production tier. 


\subsection{Homogenous Capacity Across Producers}

Consider the scenario in which there are $m$ producers in the production tier, a single product is manufactured and all producers have equal variable manufacturing costs and equal capacity so that $v_{i}=v$ and $d_{i}=d, \forall i=1,2, \ldots, m$. In addition, there is a single raw material required (i.e., $k=1$ ), and we can assume without loss of generality that one unit of the raw material is required for one unit of the product (i.e., $r=1$ ). Further, let $p^{0}$ represent the price of this raw material. The problem for producer $i$ is:

$$
\tilde{\Pi}_{i}=\operatorname{Max}\left\{\left(a-b \sum_{i} q_{i}-\left(v+p^{0}\right)\right) q_{i}\right\}
$$

Subject to: $q_{i} \leq d$ and $q_{i} \geq 0$.

The supplier considers the following problem:

$$
\tilde{\Pi}^{o}=\operatorname{Max}\left\{\left(p^{0}-v^{o}\right) \tilde{Q}\left(p^{0}\right)\right\}
$$

Subject to: $\tilde{Q}\left(p^{0}\right) \leq d^{0}$, and $p^{0} \geq 0$.

Proposition 3. The only possible solutions for (P3) are $q_{i}^{*}=d \quad \forall i$, or $q_{i}^{*}=q^{*}<d \quad \forall i$.

Proposition 3 implies that if the supplier has capacity $d^{0}>m d$, then they would sell at price $p^{0}=p^{*}$, so that at this price, each producer would order $d$ and the total supplier production quantity corresponds to $m d$. When $d^{0} \leq m d$, then the supplier would sell at price $p^{o}$, so that $p^{*} \leq p^{o} \leq a-v$. At this price, each producer orders $q^{*}$, where $q^{*} \leq d$ and the total raw material production quantity is $m q^{*}$. Figure 1 shows the demand function faced by the monopolist supplier.

\section{INSERT FIGURE 1 ABOUT HERE}

To determine $q^{*}$ and $p^{*}$, we consider the problem for producer $i$ and note that due to Proposition 3, this now reduces to $\Pi_{i}=\left(a-b m q-v-p^{o}\right) q$. The optimal production quantity $q^{*}$ can be obtained by setting $\frac{\partial \Pi_{i}}{\partial q}=0$, so that $q^{*}=\frac{\left(a-v-p^{0}\right)}{b(m+1)}$. The total quantity of product in the market is $Q=m q^{*}=\frac{m}{(m+1)} \frac{\left(a-v-p^{0}\right)}{b}$. From Figure 1, note that $p^{0}=p^{*}$ is chosen so that $Q=\frac{m}{(m+1)} \frac{\left(a-v-p^{*}\right)}{b}=m d$. This implies that $p^{*}=a-v-b(m+1) d$. We next analyze the marginal value of capacity expansion in this context by examining the Lagrange multipliers in (P3). 
Proposition 4. At the equilibrium price, the Lagrange multipliers on the capacity constraints in the producers' decision problems (P3) are identically zero, i.e., $\lambda_{i}=0, \forall i$.

The usual interpretation of a Lagrange multiplier is that it represents the marginal increase in value resulting from a marginal change in a constrained resource. If that interpretation held here, Proposition 4 would imply that there would be no increase in value from increased production capacity, under any circumstance. We show that this is not the case under the conditions defined in Proposition 5.

Proposition 5. When the supplier's capacity constraint is not binding and when $d<d^{*}=\frac{\left(a-v-v^{o}\right)}{2 b(m+1)}$, there is a positive change in the $i^{\text {th }}$ producer's profit when its capacity is increased by $\partial, \partial \rightarrow 0$.

If a producer solves (P3) in a myopic single-tier manner, as expected by Proposition 4, the Lagrange multiplier would be zero and they could conclude that the marginal value of capacity expansion is zero. However, as shown by Proposition 5, this conclusion may not be true if we consider multi-tier effects. Propositions 4 and 5 together imply that the usual interpretation of Lagrange multipliers is not valid in this competitive, multi-tier context. In this setting, as described in the proof of Proposition 4, the best response to supplier price $p^{*}(d)$ is $q_{i}=d$. This implies that although the producers are at capacity, they would not gain by producing more. However, if $p^{*}$ were anything else, say $p^{*}(d+\delta)$, then the Lagrange multipliers will not be zero. This is shown in Proposition 5 which gives the comparative statics in equilibrium.

We now consider the supplier under the conditions outlined in Proposition 5. The supplier's initial profit is $\Pi^{O}(m d)=\left(p^{*}-v^{O}\right) m d=\left(a-v-b(m+1) d-v^{o}\right) m d$. When the supplier changes capacity to meet the increased supply requirement of $\delta$ by each of the $m$ producers, their new capacity is $m(d+\partial)$ . The resulting profit is now $\Pi^{o}(m(d+\partial))=\left(a-v-b(m+1)(d+\partial)-v^{o}\right) m(d+\partial)$. The change in profit due to this capacity change is $\lim _{\partial \rightarrow 0} \frac{\Pi^{o}(m(d+\partial))-\Pi^{o}(m d)}{\partial}=p^{*} m-b m(m+1) d$, where $p^{*}=a-v-b(m+1) d$. Therefore, $\lim _{\partial \rightarrow 0} \frac{\Pi^{o}(m(d+\partial))-\Pi^{o}(m d)}{\partial}>0$, if $p^{*}>d b(m+1)$. This will hold when the optimal supplier's price is sufficiently high, which would entice the supplier to marginally expand capacity and sell more product or when the producer's capacity $d$ is sufficiently low providing the basis for capacity expansion. This analysis shows that under these circumstances, it could be profitable 
for both producers and the supplier to expand capacity by a small amount. However, were the producers to only consider the myopic problem (P3), by Proposition 3, they might erroneously conclude that the marginal value of capacity expansion is zero. This could lead to the scenario when both the supplier and producers may not even marginally increase their capacity, when this could be profitable for both of them.

\subsection{Heterogeneous Capacity Across Producers}

Now consider a scenario in which capacity differs across the producers, but without loss of generality the producers still have identical variable manufacturing costs. The problem for producer $i$ is now given by

$$
\hat{\Pi}_{i}=\operatorname{Max}\left\{\left(a-b \sum_{i} q_{i}-(v+p)\right) q_{i}\right\}
$$

Subject to: $q_{i} \leq d_{i}$ and $q_{i} \geq 0$.

The supplier considers the following problem:

$$
\hat{\Pi}^{o}=\operatorname{Max}\left\{\left(p^{o}-v^{o}\right) \hat{Q}\left(p^{0}\right)\right\}
$$

Subject to: $\hat{Q}\left(p^{0}\right) \leq d^{0}$ and $p^{0} \geq 0$.

Note that (P6) is similar in structure to (P4), but the imputed demand function $\hat{Q}\left(p^{0}\right)$ is different. Figure 2 shows the demand function for this case. We explain how Figure 2 is constructed in the Supplemental Online Appendix and show that the demand function $\hat{Q}\left(p^{0}\right)=\min _{u=1 \text { to } m}\left\{Q_{u}\left(p^{0}\right)\right\}$. Here each line segment $Q_{u}\left(p^{0}\right)=C_{u}-D_{u} p^{0}$, with $\quad C_{u}=\left(\frac{m-u+1}{m-u+2}\right)\left(\frac{a-v-b \sum_{i=1}^{u-1} d_{i}}{b}\right)$ and $D_{u}=\left(\frac{m-u+1}{m-u+2}\right)\left(\frac{1}{b}\right)$. In addition, $Q_{u}\left(p^{0}\right)$ is defined in the range $Q_{u}<Q_{u}\left(p^{0}\right)<Q_{(u-1)}, \forall u=$ 1 to $m$., where the break points $Q_{u}=\sum_{i=1}^{u-1} d_{i}+(m-u+1) d_{u}$ for $u=1$ to $m$ and $Q_{0}=0$.

The corresponding inverse demand function for the raw material is $p_{u}(Q)=A_{u}-B_{u} Q$, where $A_{u}=\left(a-v-b \sum_{i=1}^{u-1} d_{i}\right)$ and $B_{u}=\frac{b(m-u+2)}{(m-u+1)}$. Here, each line segment $p_{u}(Q)$ is defined in the range 
$p_{u}^{o}<p_{u}(Q)<p_{(u-1)}^{o}$, where break points $p_{u}^{0}=a-v-b \sum_{i=1}^{u-1} d_{i}-b(m+2-u) d_{u}$ for $u=1$ to $m$ and $p_{0}^{0}=a-v$.

\section{INSERT FIGURE 2 ABOUT HERE}

Proposition 6. The supplier's problem with heterogeneous capacity across producers is a concave optimization problem.

Proof of Proposition 6. Provided in the supplemental on-line appendix.

The proof of Proposition 6 shows that the equilibrium solution can either lie at a break point on the demand curve for the supplier at which some producer $w$ just reaches capacity, or between break points ( $w-1)$ and $w$ for some $w$ at which producers 1 to (w-1) are at capacity, while producers $w$ to $m$ are below capacity. We denote the $w^{\text {th }}$ producer as the marginal producer and let $\gamma_{w}$ be the marginal value of capacity expansion at the two cases of the equilibrium solution. Further, let $\lambda_{w}$ denote the Lagrange multiplier got by solving (P5) for firm $w$.

Proposition 7: When the equilibrium solution lies between the $(w-1)^{\text {th }}$ and $w^{\text {th }}$ break point, $\lambda_{i}=\gamma_{i}=0, \forall i=w$ to $m$ and $\lambda_{i}<\gamma_{i}, \forall i=1$ to $w-1$, where $\gamma_{i}=\lambda_{i}+b \frac{(m-w+2)}{(m-w+1)}$.

Proof of Proposition 7. Provided in the supplemental on-line appendix.

Observe from Proposition 7 that $\gamma_{i}=\lambda_{i}+b \frac{(m-w+2)}{(m-w+1)}$, which represents the additional value of capacity expansion to this producer due to the competitive interactions between producers for the raw material. Note that this additional value increases as the number of producers who are at capacity increase (i.e., as (w-1) increases), so that this producer uses this additional capacity to strengthen their market position. The multiplier $\lambda_{i}$ does not capture this effect and thus caution must be used when we interpret this parameter in this multi-tier, competitive context.

Now consider the supplier. Initially, the optimal profit for the supplier is $\hat{\Pi}^{o}=\left(\hat{p}^{0}-v_{O}\right) \hat{Q}$. If the supplier increases the supply of raw material to accommodate producer $i$, then the supplier's profit is $\hat{\Pi}_{\text {new }}^{\mathrm{o}}=\left(\hat{\mathrm{p}}^{0}-\mathrm{v}_{\mathrm{o}}-\left(\mathrm{b}+\mathrm{B}_{\mathrm{w}}\right) \partial\right)(\hat{\mathrm{Q}}+\partial) . \quad$ Therefore, $\quad \lim _{\partial \rightarrow 0} \frac{\hat{\Pi}^{\mathrm{o}}-\hat{\Pi}_{\mathrm{new}}^{\mathrm{o}}}{\partial}=\left(\hat{p}^{0}-v_{o}\right)-$ 
$\left(A_{w}+v_{o}\right) \frac{(m-w+3 / 2)}{(m-w+2)}$. This implies that $\lim _{\partial \rightarrow 0} \frac{\hat{\Pi}^{o}-\hat{\Pi}_{\text {new }}^{o}>0,}{\partial}$ if
$\left(\hat{p}^{0}-v_{O}\right)>\left(A_{w}+v_{o}\right) \frac{(m-w+3 / 2)}{(m-w+2)}$. This inequality shows that it is profitable for the supplier to increase the raw material supply to accommodate producer $i$ when the existing profit margin is greater than a threshold. Note that as $w$ or the number of producers who are at capacity increases, this threshold decreases. This is because the price reduction due to increase in supply affects only producers who are not at capacity and now this would impact fewer high volume producers who are not yet at capacity. This analysis shows that while it is possible that both the producer and the supplier can make higher profits, solving the myopic, single-tier problem underestimates the marginal value of capacity expansion and the producers, if myopic, may not choose to increase capacity.

Proposition 8: When the equilibrium solution lies at the $w^{\text {th }}$ break point, $\lambda_{i}=\gamma_{i}=0, \forall i=w+1$ to $m$ and $\lambda_{i}<\gamma_{i}, \forall i=1$ to $w$, where $\gamma_{i}=\lambda_{i}+b d_{i}$.

Proof. Provided in the supplemental on-line appendix.

Observe from Proposition 8 that $\gamma_{i}=\lambda_{i}+b d_{i}$, which represents the additional value of capacity expansion to this producer due to the competitive interactions between producers for the raw material. The multiplier $\lambda_{i}$ will not capture this effect and thus caution must be used when we interpret this parameter in this multi-tier, competitive context.

Now consider the supplier. Initially, the optimal profit for the supplier is $\hat{\Pi}^{o}=\left(p_{w}^{0}-v_{o}\right) Q_{w}$. If the supplier increases the supply of raw material to accommodate producer $w$, then the supplier's profit is now $\hat{\Pi}_{\text {new }}^{\mathrm{o}}=\left(\mathrm{p}_{\mathrm{w}}^{0}-\mathrm{v}_{\mathrm{o}}-\mathrm{b} \partial(\mathrm{m}-\mathrm{w}+2)\right)\left(\mathrm{Q}_{\mathrm{w}}+(\mathrm{m}-\mathrm{w}+1) \partial\right)$. Therefore, $\lim _{\partial \rightarrow 0} \frac{\hat{\Pi}^{\mathrm{o}}-\hat{\Pi}_{\mathrm{new}}^{\mathrm{o}}}{\partial}=$ $\left(p_{w}^{0}-v_{o}\right)-b \frac{(m-w+2)}{(m-w+1)} Q_{w} . \quad$ This implies that $\quad \lim _{\partial \rightarrow 0} \frac{\hat{\Pi}^{o}-\hat{\Pi}_{\text {new }}^{o}}{\partial}>0, \quad$ if $\left(p_{w}^{0}-v_{o}\right)>b \frac{(m-w+2)}{(m-w+1)} Q_{w}$. This inequality shows that it is profitable for the supplier to accommodate producer $w$ only when the current profit margin is greater than a threshold. Note that, unlike the case when the solution is in between break points, as $w$ or the number of producers who are at capacity increases, this threshold also increases. This is because there would be fewer producers to sell the additional supply, while price reduction due to this additional supply is felt across all producers. This analysis again shows that while it is possible that both the producer and supplier can increase their profits, 
the producer may not increase capacity even by a small amount, perhaps because solving the myopic, single-tier problem underestimates the marginal value of capacity expansion and because they are also unsure if the supplier would provide additional raw material.

In both the scenarios discussed in Propositions 7 and 8, predicting whether the supplier would provide additional raw material is complicated. This is because it requires knowledge of the raw material supplier's margin and demand function, and understanding whether the raw material price is located at a break point or at a line segment and knowing how many producers are below and above this region. This, coupled with the underestimation of the marginal value of expansion at the producers tier, may explain in part why both producers and the supplier could be reluctant to increase capacity even by small amounts. Such reluctance is particularly evident in the US petro-refining industry where the last refinery was built in 1976 (Hargreaves, 2007).

\section{COMPUTATIONAL METHOD}

We next develop a method to solve the general versions of the producer's problem (i.e. (P1)) and the supplier's problem (i.e. (P2)). For raw material prices $p^{k}, k=1$ to $r$, the equilibrium production quantities are given by (6). Let $s_{i}$ be the slack variable associated with capacity constraint (2). The complimentary slackness conditions associated with these constraints at the equilibrium production quantities are:

$$
\begin{array}{ll}
\sum_{j=1}^{n} c_{i j} q_{i j}^{*}+s_{i}=d_{i}, & \forall i=1 \text { to } m, \text { and } \\
\lambda_{i} s_{i}=0 & \forall i=1 \text { to } m .
\end{array}
$$

Rather than explicitly construct the inverse demand function, $Q^{k}\left(p^{k}\right)$, required to solve (P2) and determine the optimal $p^{k}, \forall k$, we implicitly represent this function by defining $Q^{k}=\sum_{i=1}^{m} \sum_{j=1}^{n} r_{i j k} q_{i j}^{*}$ and introduce this as constraints along with (6), (14) and (15) in (P2) to get:

$$
\left.\Pi^{o}=\operatorname{Max} \sum_{k=1}^{r}\left\{\left(p^{k}-v^{k}\right) Q^{k}\right)\right\}
$$

Subject to (6), (14), (15), and:

$$
\begin{array}{ll}
\sum_{k=1}^{r} c^{k} Q^{k} \leq d^{o}, & \\
Q^{k}=\sum_{i=1}^{m} \sum_{j=1}^{n} r_{i j k} q_{i j}^{*}, & \forall k, \\
p^{k}, \lambda_{i}, s_{i} \geq 0, & \forall i, k .
\end{array}
$$


Proposition 9. Solving (P7) is equivalent to solving (P1) and (P2).

Proof. Observe that (P7) consists of (P2) and definitional constraints (6), (14) and (15) that represent the optimal solution of (P1) that is obtained for any value of $p^{k}$, including its optimal value. Therefore solving (P7) is equivalent to solving (P1) and (P2).

We tried to solve realistic sized instances of (P7) using leading commercial software programs such as GAMS (Brooke et al. 1992) and CPLEX (1995) loaded on a Dell Optiplex PC. However, we were unable to generate feasible solutions due to complementarity constraints (15). In general, solving non linear programs with complementarity constraints are complicated and require specialized techniques (Harker and Pang, 1990). Consequently, we developed a procedure to solve (P7). The following steps outline this procedure.

Step 1: Initialization: Set $\alpha=0, \lambda_{i}^{0}=0$ and $\lambda_{i}=\lambda_{i}^{(\alpha)}=0$.

Step 2: Solve:

$$
\left.\Pi^{o}=\operatorname{Max} \sum_{k=1}^{r}\left\{\left(p^{k}-v^{k}\right) Q^{k}\right)\right\}
$$

Subject to: (6), (16), (17) and $p^{k} \geq 0, \forall k$.

Note that in (P8), $Q^{k}$ can be substituted in the objective function and in (16) using (6) and (17). This reduces (P8) to a standard concave quadratic programming problem in $p^{k}$, which can be solved using commercially available software such as Matlab (MathWorks Inc. 1998). Let $\hat{p}^{k} \forall k$ represent the optimal solution to this problem.

Step 3: Use $\hat{p}^{k}$ in (6) to find $\widehat{q}_{i j}^{*}, \forall i, j$. and use $\hat{q}_{i j}^{*}$ in (17) to find $\hat{Q}^{k}$.

Step 4: Use $\widehat{q}_{i j}^{*}$ in (16) to compute $\widehat{s}_{i} \forall i$. Let $P=\left\{p \mid \widehat{s}_{p}<0\right\}$. If $\mathrm{P}=\{\}$, set $\lambda_{i}=0, \forall i$ and stop. Otherwise, set $\lambda_{i}=0, \forall i \notin P$ and $\lambda_{i}^{(\alpha+1)}=\lambda_{i}^{(\alpha)}+\partial, \partial \in R^{+}$, set $\lambda_{i}=\lambda_{i}^{(\alpha+1)}, \alpha \rightarrow \alpha+1, \quad \forall$ $i \in P$. Go to Step 2 .

Proposition 10. Steps 1 through 4 provide an optimal solution to (P7).

Proof. Observe that for any value of raw material prices $p^{k}, \forall k$, the producer's problem is a concave optimization problem. Therefore, the Kuhn-Tucker conditions are necessary and sufficient for this problem. Since this procedure enforces the Kuhn-Tucker conditions for any value of raw material prices, including the optimal raw material prices $\hat{p}^{k}, \forall k$, this procedure provides an optimal solution to (P7). 
In light of Propositions 9 and 10, we can use this procedure to find the optimal solution to problems (P1) and (P2). We use this procedure in the following illustrative example.

\subsection{AN ILLUSTRATIVE EXAMPLE}

To better understand how production efficiencies (i.e., supplier's and producers' unit production costs) and market parameters (i.e., market size and customer price sensitivity) affect price, production quantities and profits at both the supplier and producers tiers, we considered a ten-producer, three-product, one-raw material problem. This example was chosen to be realistic and correspond to the ten major petrochemical refining companies in the United States (Platts, 2006), each of whom produce three grades of gasoline (i.e., regular, plus and supreme) refined from crude oil (i.e., raw material). The parameters used in this example are summarized in Table 1.

\section{INSERT TABLE 1 ABOUT HERE}

For this example, we first solved (P7) using Steps 1 through 4 of this procedure, which was programmed in Matlab. We then changed the supplier's unit production cost from the base level in increments of $10 \%$ from $-50 \%$ to $50 \%$. Figure 3 illustrates the corresponding change in price and production quantity for the raw material and products. As expected, the price of the raw material increases with an increase in raw material unit production costs. But this, in turn, leads to less demand for the raw material and, consequently, lower profits for the supplier. For the producer, an increase in raw material price increases the price offered to end customers. This lowers end customer demand and hence their production quantities for the products. However, the impact on producer's profit depends on the consumption factor (i.e., $r_{i j k}$ ) representing the rate at which the raw material is consumed by the producer to provide the end product. In particular, profits go up for producers with lower consumption factors, while they go down for producers with higher consumption factors. The implications in the petro-refining industry are that producers could benefit from technologies that decrease consumption factors (i.e., improve yields) particularly when raw material prices (i.e., crude prices) increase.

\section{INSERT FIGURE 3 ABOUT HERE}

To understand the impact of a producer's unit production costs on price, quantity and profit at the supplier and producers, we varied the value of this parameter across the three products and ten producers from the base level in increments of $10 \%$ from $-50 \%$ to $50 \%$. Figure 4 illustrates the corresponding change in price and production quantity for the raw material and products, and the resulting profits for the supplier and producers. With an increase in unit production costs at the producer, these costs are passed on to customers and end product prices increase. This reduces end product demand and consequently the producer's production quantity. This in turn leads to a decline in producer's profits. As the total 
production quantities decrease, demand for raw material decrease, which causes raw material production quantities and prices to drop. This contributes to a decline in supplier profits. Thus, a decrease in production efficiencies at the producers causes profits for both the supplier and producers to decline.

\section{INSERT FIGURE 4 ABOUT HERE}

Finally, we wanted to analyze how market size and customer price sensitivity affect price, production quantity and profit at the supplier and producers. Recall that the market size and customer price sensitivity for product $j$ are $a_{j} / b_{j}$, and $1 / b_{j}$, respectively. To vary market size for a product, we varied $a_{j}$ across the three products from the base level in increments of $10 \%$ from $-50 \%$ to $50 \%$. This analysis showed that as market size increased, as expected, prices, production quantities and profits increased at both the supplier and the producers, and the converse also holds. This seems consistent with trends in the petrochemical industry. Here, an increase in market size due to emerging markets like China and due to gas guzzling vehicles such as SUV's (U.S. Census Bureau News, 2004), has been observed to increase prices, production quantities and profits for refiners and the crude oil supplier (Energy Information Administration, 2006). We also analyzed the impact of customer price sensitivity by varying $b_{j}$ across the three products from the base level in increments of $10 \%$ from $-50 \%$ to $50 \%$. Here, we also changed $a_{j}$ as required to ensure that market size remained unchanged. This analysis showed that as customer price sensitivity decreased, prices, production quantities and profits increased at both the supplier and the producers, and the converse also holds. Again, this seems consistent with trends in the petrochemical industry, in which customers seem more insensitive to gas prices due to life style choices (Victorian Transport Policy Institute, 2005) and this has led to an increase in prices, production quantities and profits for refiners and the crude oil supplier (Energy Information Administration, 2006).

\section{CONCLUSIONS}

We have considered a competitive version of the traditional aggregate production planning with capacity constraints. We develop a model to include interactions with the raw material supplying sector for which supplies are limited and prices reflect these limitations. Here, we use a successive "BertrandCournot" framework in which a monopolist supplier sets raw material prices to maximize profits so that the raw material production quantity equals the total requirements across all producers. Given these raw material prices, the producers solve the Cournot game to determine the optimal production quantities by allocating capacity across a set of products.

To understand the strategic interactions between the raw material supplier and the product processing tier, we examine simplified versions of this problem. In particular, we consider the single-raw-material, single-product problem with homogenous and heterogeneous capacity across producers. When producers are homogenous with respect to capacity limits, there are systematic situations for which Lagrange 
multipliers for capacity constraints are zero, but a marginal increase in capacity can result in positive benefits for the producers. Therefore, the usual interpretation of Lagrange multipliers is not valid. We also show that it is profitable for the supplier to increase capacity marginally and supply to the producers when the optimal price set by the supplier is high or the producer's capacity is sufficiently low. While such marginal increases in capacity could be profitable to both the supplier and producers, this is not apparent if the producer does not consider multi-tier effects in their decision making process.

We further show that when producers are heterogeneous with varying capacity constraints, Lagrange multipliers are not generally zero, but again, their interpretation requires care. In particular, we show that the multiplier does not capture the additional value of capacity for the producer due to competitive interactions between producers for the raw material used. We also show that it is profitable for the supplier to marginally increase capacity when the profit margin on the raw material is greater than a threshold; and this threshold changes with the number of producers at capacity. Here again, we find that while capacity expansion could be profitable for both the supplier and producers, this is not evident if the producer does not consider multi-tier effects in their decision making process.

We also present a computational method to solve the general problem. We use this method on an illustrative example to better understand how production efficiencies at the supplier and producers affect production quantities and prices of the raw material and the product, and profits at the supplier and producer's tiers. We also consider the impact of market size and customer price sensitivity on these aspects.

This paper presents several avenues for future research. First, this problem could be extended to incorporate multi-period effects using inventory constraints. Second, we could consider the impact of yield uncertainty at both the supplier and producer tiers. Both these extensions would require significant modifications to the computational method to solve the general problem. Finally, another direction could be to extend this problem to multiple suppliers and producers. In this case, the entire structure of the supplier problem has to be changed, as price competition with more than one supplier would lead to marginal cost pricing. One plausible approach could be to change the supplier problem to quantity rather than price competition. However, the optimal solution for such a problem may not be always computable, as in general, the raw material demand function may not be invertible. We hope this paper provides the stimulus and building blocks to examine these new, exciting and challenging avenues for future research.

\section{REFERENCES}

Abiru, Masahiro. 1988. "Vertical Integration, Variable Proportions and Successive Oligopolies.” The Journal of Industrial Economics. 36: 315-325. 
Bernstein, F. and G. A. DeCroix. 2004. "Decentralized Pricing and Capacity Decisions in a Multitier System with Modular Assembly.” Management Science, 50, (9): 1293-1308

Bernstein, F. and A. Federgruen. 2005. "Decentralized Supply Chains with Competing Retailers under Demand Uncertainty.” Management Science, 51, (1): 18-29

Bresnahan, T. F., P. C. Reiss. 1985. "Dealer and manufacturer margins.” Rand Journal of Economics. 16(2), 253-268.

Brooke, A., Kendrick, D. and Meeraus A., (1992), GAMS: A User's Guide, The Scientific Press, San Francisco, California.

Carr, S., U.S. Karmarkar. 2005. “Competition in Multi echelon Assembly Supply Chains.” Management Science, 51 (1):45-59

Corbett, C. and U.S. Karmarkar. 2001. "Competition and Structure in Serial Supply Chains." Management Science. 47: 966-978.

Cournot, A. 1838. Recherches sur les Principes Mathematiques de la Theorie des Richesses. Paris. English translation: N. Bacon. 1897. Researches into the Mathematical Principles of the Theory of Wealth. MacMillan, New York.

Coy, P. March 29, 2004. “Are Refineries Boosting the Pain at the Pump?” Business Week.

CPLEX Optimization Inc. (1995), CPLEX Version 4.0 Manual, Incline Village, NV, USA.

Dutta G and Fourer R (2004). "An optimization based decision support system for strategic and operational planning in process industries”. Optimization and Engineering. 5(3):295-314.

Dutta G, Fourer R, Majumdar A and Dutta D (2007). “An optimization based decision support system for strategic and operational planning within process industries: case of pharmaceuticals industry in India.” International Journal of Production Economics. 102: 92-103.

Dauzere-Peres, S. and Lasserre, J.B. (1994). An Integrated Approach in Production Planning and Scheduling. Berlin, Springer-Verlag.

Energy Information Administration. 2006. Official Energy Statistics from the U.S. Government. http://tonto.eia.doe.gov/dnav/pet/pet_cons_psup_dc_nus_mbbl_a.htm; http://www.eia.doe.gov/emeu/finance/

Friedman, J. 1986. Game Theory with Applications to Economics. Oxford University Press. New York.

Greenhut, M.L. and H. Ohta. 1979. "Vertical Integration of Successive Oligopolists.” American Economic Review. 69: 137-141.

Griffin, J.M. 1985. “OPEC Behavior: A Test of Alternate Hypothesis.” American Economic Review. 75: 954-963.

Grossman, S. J., O. D. Hart. 1986. "The costs and benefits of ownership: a theory of vertical and lateral integration.” Journal of Political Economy. 94(4) 691-719. 
Hanssmann, F. and S.W. Hess. 1960. "A Linear Programming Approach to Production and Employment Scheduling.” Management Technology. 1.

Hargreaves, S. 2007. http://money.cnn.com/2007/04/17/news/economy/refineries/

Harker, P.T. and J.S. Pang. 1990. "Finite-dimensional variational inequality and nonlinear complementarity problems: A survey” Mathematical Programming, 48 (1-3): 161-220.

Haskel, J. and C. Martin. 1994. “Capacity and Competition: Empirical Evidence on UK Panel Data.” The Journal of Industrial Economics. 42(1): 23-44.

Herk, L.F. Autumn 1993. "Consumer Choice and Cournot Behavior in Capacity-Constrained Duopoly Competition.” The RAND Journal of Economics. 24(3): 399-417.

Holt, C.C., F. Modigliani, J.F. Muth and H.A. Simon. 1960. Planning Production, Inventories and Work Force. Prentice-Hall. Englewood Cliffs, NJ.

Karmarkar, U.S. and R. Pitbladdo. 1993. "Internal Pricing and Cost Allocation in a Model of Multiproduct Competition with Finite Capacity Increments.” Management Science. 39: 1039-1053.

Karmarkar, U.S. and R. Pitbladdo. 1994. "Product Line Selection, Production Decisions and Allocation of Common Fixed Costs.” International Journal of Production Economics. 34: 17-33.

Lasdon, L.S. and R.C. Terjung. 1971. “An Efficient Algorithm for Multi-Item Scheduling.” Operations Research. 19(4): 946-969.

Machlup, F. and M. Taber. 1960. "Bilateral Monopoly, Successive Monopoly, and Vertical Integration.” Economica. 27: 101-119.

MathWorks Inc. 1998. The Mathlab Curriculum Series. Users Guide.

Morrison, K. October 6, 2005. “Supply Concerns Push Copper to a Record High.” Financial Times.

Nam, S. and R. Logendran. 1992. "Aggregate Production Planning - A Survey of Models and Methodologies.” European Journal of Operations Research. 61: 255-272.

Platts. 2006. http://www.platts.com/top250/index.xml

Pochet, Y. and Wolsey,L.A, 2006. Production Planning by Mixed Integer Programming, Springer.

U.S. Census Bureau News. 2004. http://www.census.gov/Press-Release/www/releases/archives/transportation_industry/003127.html

Victorian Transport Policy Institute. April 26, 2006. Transportation Elasticities: How Prices and Other Factors Affect Travel Behavior. http://www.vtpi.org/elasticities.pdf

Zappe, C. and I. Horowitz. 1993. "Quasi-Cournot Behavior in a Multimarket, Multiplant Setting." Managerial and Decision Economics. 14(1): 75-81.

Ziss, S., 1995. "Vertical Separation and Horizontal Mergers," Journal of Industrial Economics, 43, 63-75. 
FIGURE 1. Demand Function $\widetilde{Q}\left(P^{0}\right)$ for the Supplier With Homogenous Producers

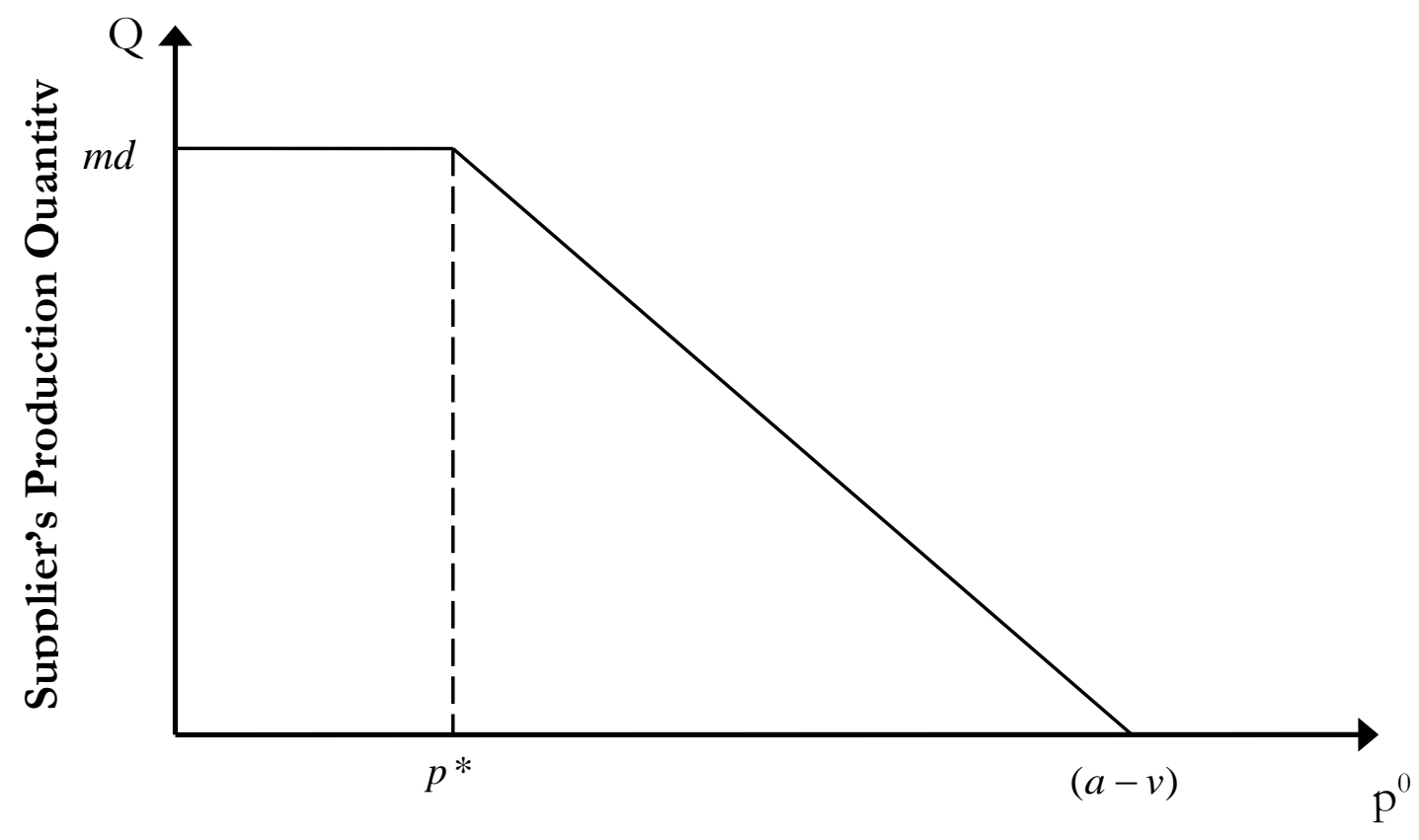

Supplier's Price

FIGURE 2. Demand Function $\widehat{Q}_{1}\left(P^{0}\right)$ for the Supplier With Heterogeneous Producers

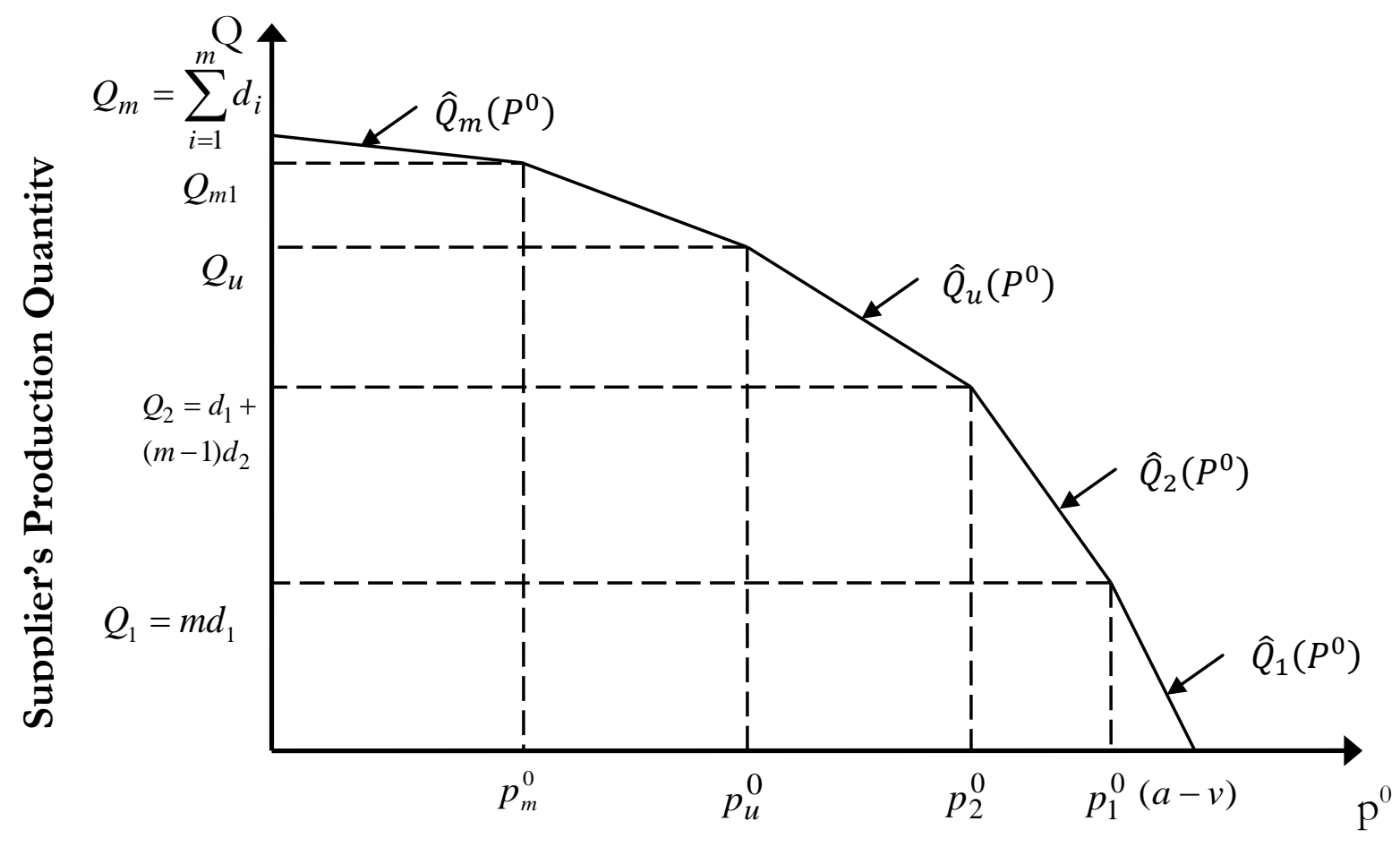

Supplier's Price 
FIGURE 3: Change in Prices and Production Quantities with Changes in Unit Costs of Raw Material

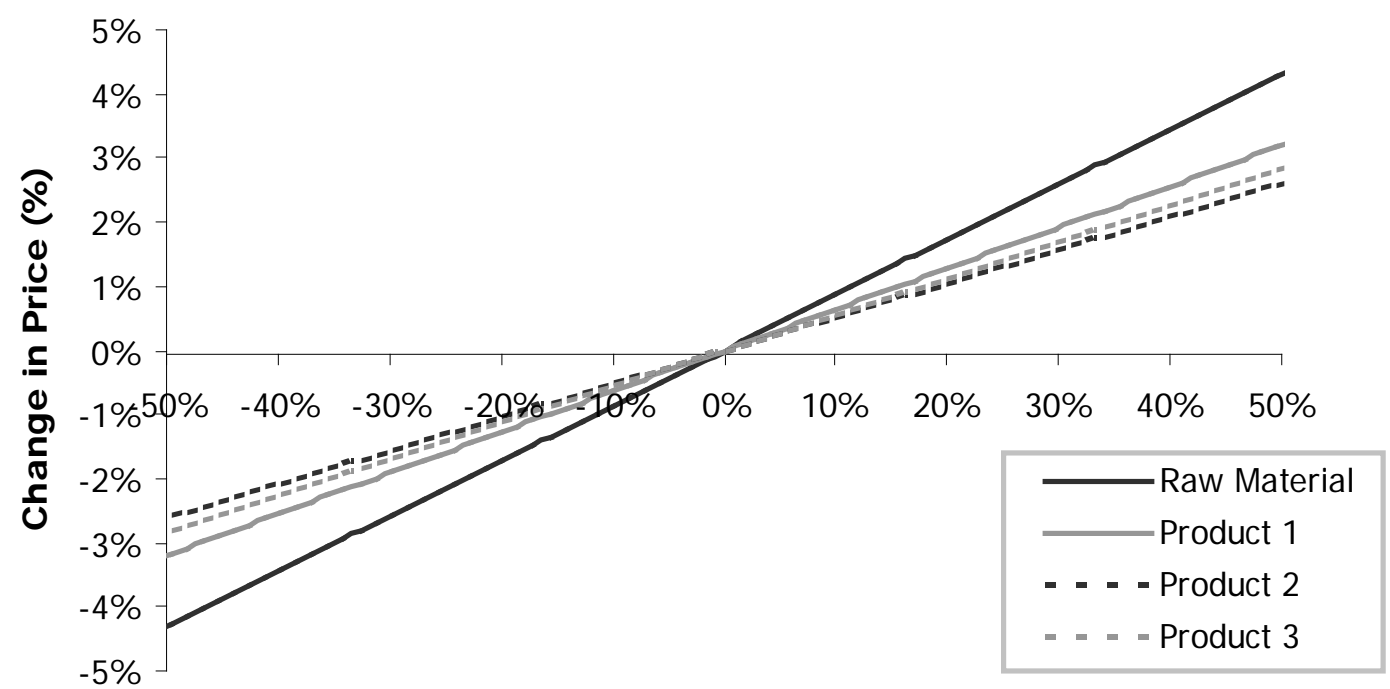

Change in Unit Raw Material Production Costs (\%)

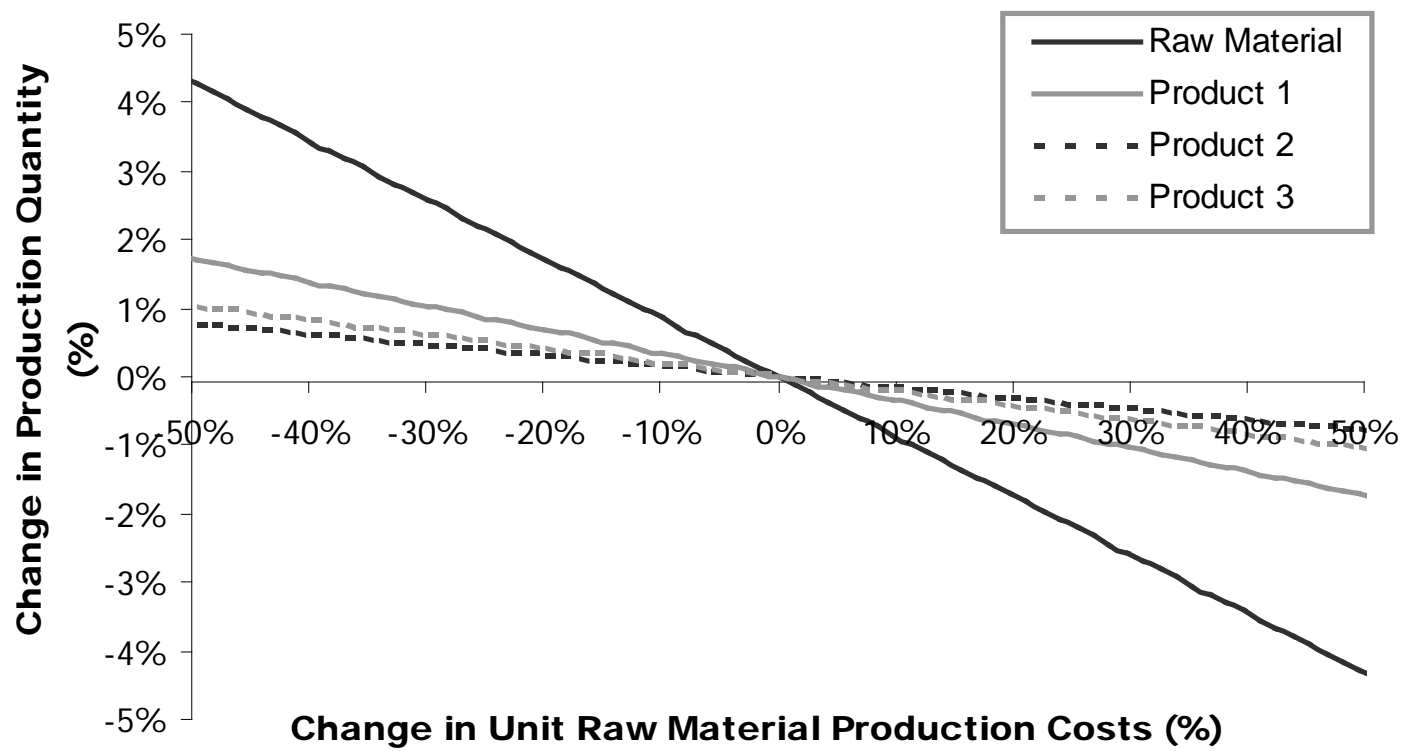


FIGURE 4: Change in Prices, Production Quantities and Profits with Changes in Unit Costs of Products
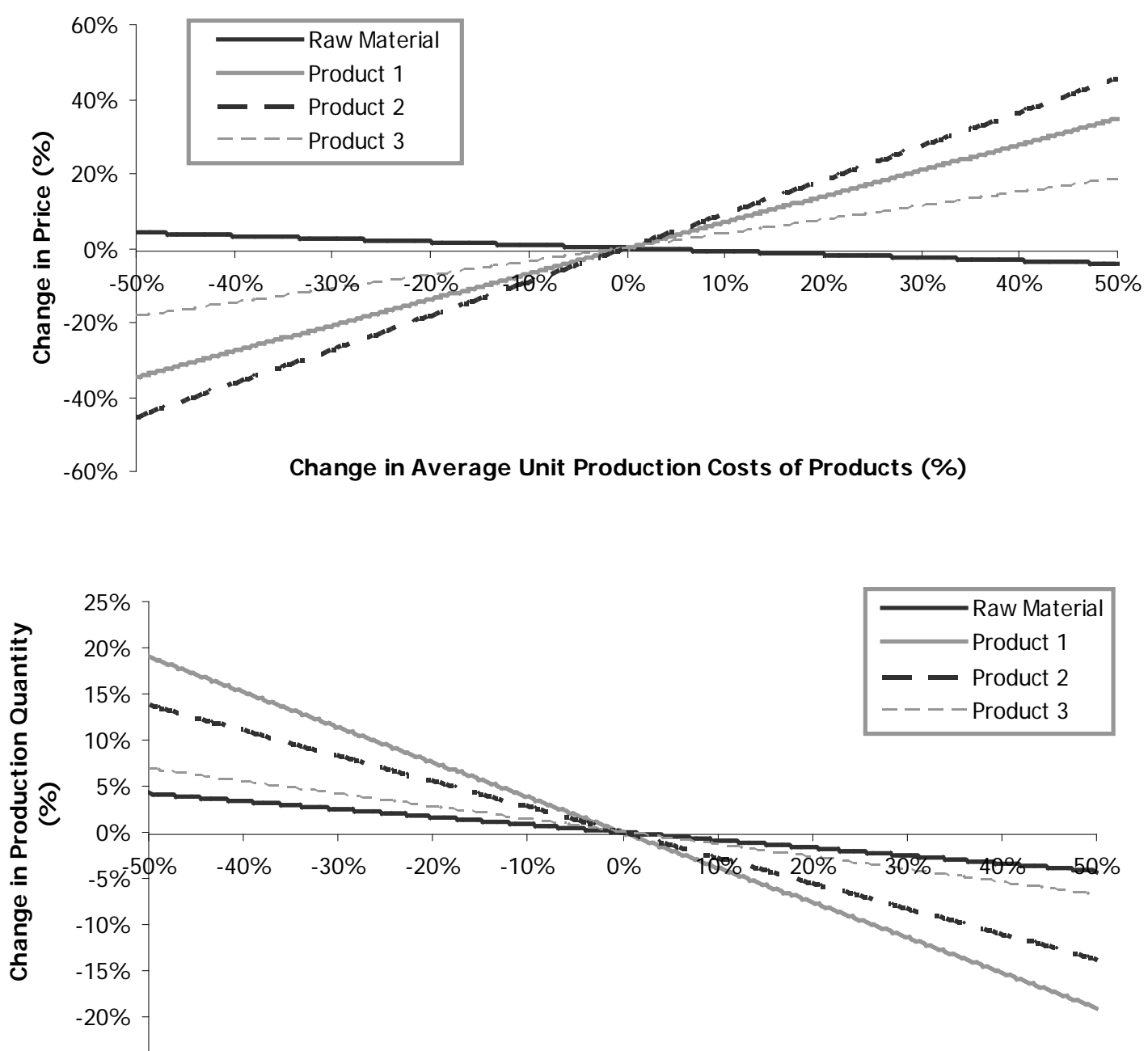

$-25 \% \quad$ Change in Average Unit Production Costs of Products (\%)

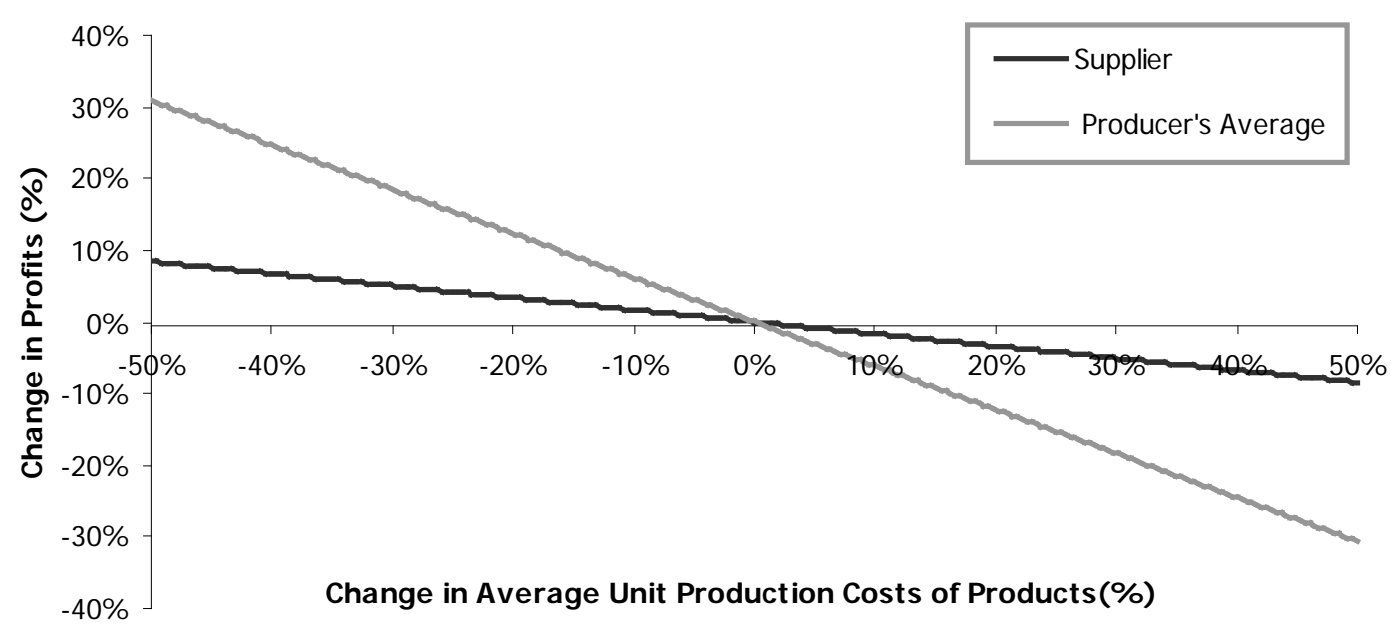


TABLE 1: Summary of Parameters Used in Illustrative Example

\begin{tabular}{|l|l|}
\hline Producers & $\mathrm{m}=10 ; \mathrm{i}=1$ to 10 \\
\hline Products & $\mathrm{n}=3 ; \mathrm{j}=1$ to 3 \\
\hline Raw Materials & $\mathrm{r}=1 ; \mathrm{k}=1$ \\
\hline Raw Material Cost Per Unit & $\mathrm{v}^{1}=1$ \\
\hline $\begin{array}{l}\text { Capacity Required to Produce Unit of Raw } \\
\text { Material }\end{array}$ & $\mathrm{c}^{1}=1$ \\
\hline Total Capacity Available at Supplier & $\mathrm{d}^{0}=11000$ \\
\hline
\end{tabular}

\begin{tabular}{|c|c|c|c|c|c|c|c|c|c|c|}
\hline Producer & $i=1$ & $i=2$ & $i=3$ & $\mathrm{i}=4$ & $i=5$ & $i=6$ & $\mathrm{i}=7$ & $i=8$ & $i=9$ & $\mathrm{i}=10$ \\
\hline $\begin{array}{l}\text { Production Cost } \\
\text { Product } 1\end{array}$ & $\begin{array}{l}\mathrm{v}_{11}= \\
2\end{array}$ & $\begin{array}{l}\mathrm{v}_{21}= \\
0.5\end{array}$ & $\begin{array}{l}\mathrm{v}_{31}= \\
0.5\end{array}$ & $\begin{array}{l}\mathrm{v}_{41}= \\
1\end{array}$ & $\begin{array}{l}\mathrm{v}_{51}= \\
0.5\end{array}$ & $\begin{array}{l}\mathrm{v}_{61}= \\
0.5\end{array}$ & $\begin{array}{l}\mathrm{v}_{71}= \\
2.5\end{array}$ & $\begin{array}{l}\mathrm{V}_{81}= \\
0.5\end{array}$ & $\begin{array}{l}\mathrm{V}_{91}= \\
0.5\end{array}$ & $\begin{array}{l}\mathrm{V}_{(10) 1} \\
=2\end{array}$ \\
\hline $\begin{array}{l}\text { Production Cost } \\
\text { Product } 2 \\
\end{array}$ & $\begin{array}{l}\mathrm{v}_{12}= \\
1.5\end{array}$ & $\begin{array}{l}\mathrm{v}_{22}= \\
1\end{array}$ & $\begin{array}{l}\mathrm{v}_{32}= \\
1\end{array}$ & $\begin{array}{l}\mathrm{v}_{42}= \\
0.5\end{array}$ & $\begin{array}{l}\mathrm{v}_{52}= \\
2.5\end{array}$ & $\begin{array}{l}\mathrm{v}_{62}= \\
2.5 \\
\end{array}$ & $\begin{array}{l}\mathrm{v}_{72}= \\
1\end{array}$ & $\begin{array}{l}\mathrm{V}_{82}= \\
1.5\end{array}$ & $\begin{array}{l}\mathrm{V}_{92}= \\
0.5\end{array}$ & $\begin{array}{l}\mathrm{V}_{(10) 2} \\
=1.5 \\
\end{array}$ \\
\hline $\begin{array}{l}\text { Production Cost } \\
\text { Product } 3\end{array}$ & $\begin{array}{l}\mathrm{v}_{13}= \\
1\end{array}$ & $\begin{array}{l}\mathrm{v}_{23}= \\
2\end{array}$ & $\begin{array}{l}\mathrm{v}_{33}= \\
2.5\end{array}$ & $\begin{array}{l}\mathrm{v}_{43}= \\
1.5 \\
\end{array}$ & $\begin{array}{l}\mathrm{v}_{53}= \\
2.5\end{array}$ & $\begin{array}{l}\mathrm{v}_{63}= \\
2\end{array}$ & $\begin{array}{l}\mathrm{v}_{73}= \\
0.5\end{array}$ & $\begin{array}{l}\mathrm{V}_{83}= \\
2.5\end{array}$ & $\begin{array}{l}\mathrm{V}_{93}= \\
0.5\end{array}$ & $\begin{array}{l}\mathrm{V}_{(10) 3} \\
=2\end{array}$ \\
\hline $\begin{array}{l}\text { Raw Material } \\
\text { Consumption } \\
\text { Factor - Product } 1 \\
\end{array}$ & $\begin{array}{l}\mathrm{r}_{111}= \\
0.03\end{array}$ & $\begin{array}{l}\mathrm{r}_{211}= \\
0.03\end{array}$ & $\begin{array}{l}\mathrm{r}_{311}= \\
0.02\end{array}$ & $\begin{array}{l}\mathrm{r}_{411}= \\
0.02\end{array}$ & $\begin{array}{l}\mathrm{r}_{511}= \\
0.02\end{array}$ & $\begin{array}{l}\mathrm{r}_{611}= \\
0.02\end{array}$ & $\begin{array}{l}\mathrm{r}_{711}= \\
0.01\end{array}$ & $\begin{array}{l}\mathrm{r}_{811}= \\
0.01\end{array}$ & $\begin{array}{l}\mathrm{r}_{911}= \\
0.03\end{array}$ & $\begin{array}{l}\mathrm{r}_{(10) 11} \\
=0.02\end{array}$ \\
\hline $\begin{array}{l}\text { Raw Material } \\
\text { Consumption } \\
\text { Factor - Product } 2\end{array}$ & $\begin{array}{l}\mathrm{r}_{121}= \\
0.01\end{array}$ & $\begin{array}{l}\mathrm{r}_{221}= \\
0.01\end{array}$ & $\begin{array}{l}\mathrm{r}_{321}= \\
0.01\end{array}$ & $\begin{array}{l}\mathrm{r}_{421}= \\
0.02\end{array}$ & $\begin{array}{l}\mathrm{r}_{521}= \\
0.02\end{array}$ & $\begin{array}{l}\mathrm{r}_{621}= \\
0.01\end{array}$ & $\begin{array}{l}\mathrm{r}_{721}= \\
0.03\end{array}$ & $\begin{array}{l}\mathrm{r}_{821}= \\
0.01\end{array}$ & $\begin{array}{l}\mathrm{r}_{921}= \\
0.02\end{array}$ & $\begin{array}{l}\mathrm{r}_{(10) 21} \\
=0.01\end{array}$ \\
\hline $\begin{array}{l}\text { Raw Material } \\
\text { Consumption } \\
\text { Factor - Product } 3 \\
\end{array}$ & $\begin{array}{l}\mathrm{r}_{131}= \\
0.01\end{array}$ & $\begin{array}{r}\mathrm{r}_{231}= \\
0.03\end{array}$ & $\begin{array}{l}\mathrm{r}_{331}= \\
0.01\end{array}$ & $\begin{array}{l}\mathrm{r}_{431}= \\
0.03\end{array}$ & $\begin{array}{l}\mathrm{r}_{531}= \\
0.02\end{array}$ & $\begin{array}{l}\mathrm{r}_{631}= \\
0.02\end{array}$ & $\begin{array}{l}\mathrm{r}_{731}= \\
0.02\end{array}$ & $\begin{array}{l}\mathrm{r}_{831}= \\
0.01\end{array}$ & $\begin{array}{l}r_{931}= \\
0.02\end{array}$ & $\begin{array}{l}r_{(10) 31} \\
=0.02\end{array}$ \\
\hline $\begin{array}{l}\text { Capacity Required } \\
\text { Product } 1\end{array}$ & $\begin{array}{l}\mathrm{c}_{11}= \\
1.5\end{array}$ & $\begin{array}{l}\mathrm{C}_{21}= \\
2.5\end{array}$ & $\begin{array}{l}c_{31}= \\
0.5\end{array}$ & $\begin{array}{l}\mathrm{C}_{41}= \\
2.5\end{array}$ & $\begin{array}{l}\mathrm{C}_{51}= \\
0.5\end{array}$ & $\begin{array}{l}\mathrm{C}_{61}= \\
1.5\end{array}$ & $\begin{array}{l}\mathrm{C}_{71}= \\
0.5\end{array}$ & $\begin{array}{l}\mathrm{C}_{81}= \\
2\end{array}$ & $\begin{array}{l}\mathrm{C}_{91}= \\
1\end{array}$ & $\begin{array}{l}\mathrm{C}_{(10) 1} \\
=2.5\end{array}$ \\
\hline $\begin{array}{l}\text { Capacity Required } \\
\text { Product } 2\end{array}$ & $\begin{array}{l}\mathrm{c}_{12}= \\
0.5\end{array}$ & $\begin{array}{l}\mathrm{C}_{22}= \\
1.5\end{array}$ & $\begin{array}{l}\mathrm{C}_{32}= \\
2.5\end{array}$ & $\begin{array}{l}\mathrm{C}_{42}= \\
2.5\end{array}$ & $\begin{array}{l}\mathrm{C}_{52}= \\
1\end{array}$ & $\begin{array}{l}\mathrm{C}_{62}= \\
1.5\end{array}$ & $\begin{array}{l}\mathrm{C}_{72}= \\
1.5\end{array}$ & $\begin{array}{l}\mathrm{C}_{82}= \\
0.5\end{array}$ & $\begin{array}{l}\mathrm{C}_{92}= \\
0.5\end{array}$ & $\begin{array}{l}\mathrm{C}_{(10) 2} \\
=1.5\end{array}$ \\
\hline $\begin{array}{l}\text { Capacity Required } \\
\text { Product } 3\end{array}$ & $\begin{array}{l}\mathrm{c}_{13}= \\
2\end{array}$ & $\begin{array}{l}\mathrm{C}_{23}= \\
1\end{array}$ & $\begin{array}{l}\mathrm{C}_{33}= \\
1\end{array}$ & $\begin{array}{l}\mathrm{c}_{43}= \\
1\end{array}$ & $\begin{array}{l}\mathrm{C}_{53}= \\
2.5\end{array}$ & $\begin{array}{l}\mathrm{c}_{63}= \\
2\end{array}$ & $\begin{array}{l}\mathrm{C}_{73}= \\
1\end{array}$ & $\begin{array}{l}\mathrm{C}_{83}= \\
2.5\end{array}$ & $\begin{array}{l}\mathrm{C}_{93}= \\
2\end{array}$ & $\begin{array}{l}\mathrm{C}_{(10) 3} \\
=1\end{array}$ \\
\hline Total Capacity & 1000 & 1500 & 1000 & 1500 & 1000 & 1500 & 1000 & 1500 & 1000 & 1500 \\
\hline
\end{tabular}




\section{SUPPLEMENTARY ONLINE APPENDIX}

\section{Proofs for Propositions}

Proposition 1: There exists a unique vector of equilibrium order quantities $q_{i j}^{*}, \forall i, j$.

Proof. Observe from (5) that $\sum_{j} \sum_{i} \sum_{t \neq i} \frac{\delta q_{i j}}{\delta q_{t j}} \leq 1$. By Friedman (1986), page 84, Theorem 3.4, there exists a unique equilibrium.

Proposition 2. When the capacity constraint is not binding and when production costs are equal across all producers, the monopolist produces less of the product at a higher price.

Proof. Let $\bar{v}_{j}=v_{i j}+\sum_{k=1}^{r} p^{k} r_{i j k}=v_{(N C) j}+\sum_{k=1}^{r} p^{k} r_{(N C) j k}, \forall i$ represent the production cost for product $j$, which is invariant across $m$ producers. When the capacity constraint is not binding, $\lambda_{i j}=\lambda_{(N C)}=0, \forall i, j$. Under these assumptions and using (7) and (10), we get $q_{j}^{*}=\frac{m}{(m+1)}\left(\frac{a_{j}-\bar{v}_{j}}{b_{j}}\right)>q_{(N C) j}^{*}, \forall m \geq 2 . \quad$ It $\quad$ then follows that $p_{j}^{*}=a_{j}-b_{j} q_{j}^{*}<a_{j}-b_{j} q_{(N C) j}^{*}=p_{(N C) j}^{*}, \forall m \geq 2$

Proposition 3. The only possible solutions for (P3) are $q_{i}^{*}=d \quad \forall i$, or $q_{i}^{*}=q^{*}<d \quad \forall i$.

Proof. Suppose not, $q_{i}^{*}=d \quad \exists i \neq j \quad$ and $\quad q_{j}^{*}<d$, or $\quad q_{i}^{*}>q_{j}^{*}$. Then, $\left.\frac{\partial \Pi_{i}}{\partial q_{i}}\right|_{q_{i}=q_{i}^{*}, q_{j}=q_{j}^{*}}=a-2 b q_{i}^{*}-b q_{j}^{*}-b \sum_{p \neq i, j} q_{p}-\left(v+p^{0}\right) \geq 0$,
$\left.\frac{\partial \Pi_{i}}{\partial q_{j}}\right|_{q_{j}=q_{j}^{*}, q_{i}=q_{i}^{*}}=a-2 b q_{j}^{*}-b q_{i}^{*}-b \sum_{p \neq i, j} q_{p}-\left(v+p^{0}\right)=0$.

But, this is a contradiction, if $q_{i}^{*}>q_{j}^{*}$. Therefore, the result holds. 
Proposition 4. At the equilibrium price, the Lagrange multipliers on the capacity constraints in the producers' decision problems (P3) are identically zero, i.e., $\lambda_{i}=0, \forall i$.

Proof. Observe from Figure 1, that the maximum production $d$ for each producer is achieved when $p^{0}=p^{*}=a-v-b(m+1) d$. Thus, when $p^{0}>p^{*}, q^{*}=\frac{\left(a-v-p^{0}\right)}{b(m+1)}<d$. This implies that the producer's capacity is not exceeded, the constraints in P3 are not binding even when they are tight, and by Proposition 3, this is true for all producers. Therefore, the Lagrange multipliers, $\lambda_{i}$, will always be zero for all producers.

Proposition 5. When the supplier's capacity constraint is not binding and when $d<d^{*}=\frac{\left(a-v-v^{o}\right)}{2 b(m+1)}$, there is a positive change in the $i^{\text {th }}$ producer's profit when its capacity is increased by $\partial, \partial \rightarrow 0$.

Proof. In preparation, we first obtain the solution to the supplier's problem (P4). We first substitute the demand curve $Q\left(p^{o}\right)=m q^{*}=\frac{m}{(m+1)} \frac{\left(a-v-p^{o}\right)}{b}$ into the objective function. Note that the breakpoint in this curve is accommodated by limiting the supplier's price to be greater than or equal to $p^{*}$. This is because the supplier has no incentive to choose a price less than $p^{*}$ since the total production quantities across the producers cannot increase above the capacity limit. Observe that (P4) can be written as:

$$
\begin{aligned}
\tilde{\Pi}^{o}= & \operatorname{Max}\left\{\left(p^{0}-v^{o}\right) \frac{m}{(m+1)} \frac{\left(a-v-p^{o}\right)}{b}\right. \\
& \text { Subject to: } \frac{m}{(m+1)} \frac{\left(a-v-p^{o}\right)}{b} \leq d^{0}, \text { and } p^{0} \geq p^{*} .
\end{aligned}
$$

If we assume that the constraint is not binding, the solution to (P4) is at the unconstrained optimum given by $p^{0}=\left(a-v+v^{o}\right) / 2$. Recall that $q^{*}=\frac{\left(a-v-p^{0}\right)}{b(m+1)}$. Substituting the value of the unconstrained optimum $p^{o}$ in to this expression gives $q^{*}=\frac{\left(a-v-v^{o}\right)}{2 b(m+1)}=d^{*}$. Recollect that $p^{*}$ is the price at which the solution $q^{*}$ exactly equals $d$ where $p^{*}=a-v-b(m+1) d$. 
If $d<d^{*}$ then $q^{*}>d$. Let $d=q^{*}-\delta$ and substitute this value of $d$ in $p^{*}=a-v-b(m+1) d$. Then, we get $p^{*}=p^{o}+b(m+1) \partial$ or $p^{o}<p^{*}$, where $p^{0}=\left(a-v+v^{o}\right) / 2$. In this case, the capacity constraint of the producer is binding so that $q^{*}$ will be set to $d$ and the price constraint on the supplier is binding so that $p^{o}$ will be set to $p^{*}$.

Let $\tilde{\Pi}(d)$ represent the producer's profits when capacity is $d$ and $\tilde{\Pi}(d+\partial)$ represent the profit when capacity is increased to $d+\delta$. Then:

$\tilde{\Pi}(d)=\left(a-b m d-v-p^{*}\right) d=d^{2} b$ and $\tilde{\Pi}(d+\partial)=\left(a-b m(d+\partial)-v-p^{*}\right)(d+\partial)=(d+\partial)^{2} b$,

so that $\lim _{\partial \rightarrow 0} \frac{\tilde{\Pi}(d+\partial)-\tilde{\Pi}(d)}{\partial}=2 b d>0$

Proposition 6. The supplier's problem with heterogeneous capacity across producers is a concave optimization problem.

Proof. Consider the supplier's problem with heterogeneous capacity across producers represented by (P6). In this problem, it is sufficient to show that $p^{o} \hat{Q}\left(p^{0}\right)$ is a concave function of $p^{0}$. Since $\hat{Q}\left(p^{0}\right)=\min _{u}\left\{Q_{u}\left(p^{0}\right)\right\}, \quad$ where $\quad Q_{u}\left(p^{0}\right)=C_{u}-D_{u} p^{0}, \quad$ we $\quad$ get $p^{0} \hat{Q}\left(p^{0}\right)=p_{u}^{0} \min _{u}\left\{Q_{u}\left(p^{0}\right)\right\}=\min _{u}\left\{p^{0} Q_{u}\left(p^{0}\right)\right\}=\min _{u}\left\{C_{u} p^{0}-D_{u}\left(p^{o}\right)^{2}\right\}$.

As $C_{u} p^{0}-D_{u}\left(p^{0}\right)^{2}$ is concave in $p^{0}, \forall u$, we get that $p^{0} \hat{Q}\left(p^{0}\right)$ is a concave function of $p^{0}$.

In light of Proposition 6, we can find the optimal value of (P6) using the following procedure. First, consider break points $\left(p_{u}^{0}, Q_{u}\right)$, evaluate $\hat{\Pi}\left(p_{u}^{0}, Q_{u}\right)=\left(p_{u}^{0}-v^{0}\right) Q_{u} \quad$ and $\quad$ find $\hat{\Pi}^{1}=\operatorname{Max}_{u}\left\{\hat{\Pi}\left(p_{u}^{0}, Q_{u}\right)\right\} \quad$ and $\quad$ let $\quad p_{s}^{0}=\operatorname{Arg} \max _{u}\left\{\hat{\Pi}\left(p_{u}^{0}, Q_{u}\right)\right\} . \quad$ Next, $\quad$ consider $Q_{S}\left(p^{0}\right)=C_{S}-D_{S} p^{0}$, the line segment representing the demand function bounded by the break points $\left(Q_{(s-1)}, Q_{s}\right)$ Also, consider $Q_{(s+1)}\left(p^{0}\right)=C_{(s+1)}-D_{(s+1)} p^{0}$, the line segment bounded by break points $\quad\left(Q_{s}, Q_{(s+1)}\right) . \quad$ Then, $\quad$ compute $\quad \hat{\Pi}^{2}=\operatorname{Max}\left\{C_{s} p^{0}-D_{s}\left(p^{0}\right)^{2}\right\}$, $p^{0} \geq 0$ 
$\hat{\Pi}^{3}=\operatorname{Max}\left\{C_{(s+1)}\right.$
$p^{0} \geq 0$ material price $\hat{p}^{0}=\operatorname{Arg} \max \left\{\left\{\hat{\Pi}^{1}, \hat{\Pi}^{2}, \hat{\Pi}^{3}\right)\right.$.

Proposition 7: When the equilibrium solution lies between the $(w-1)^{\text {th }}$ and $w^{\text {th }}$ break point, $\lambda_{i}=\gamma_{i}=0, \forall i=w$ to $m$ and $\lambda_{i}<\gamma_{i}, \forall i=1$ to $w-1$, where $\gamma_{i}=\lambda_{i}+b \frac{(m-w+2)}{(m-w+1)}$.

Proof. When the equilibrium solution lies between the $(w-1)^{\text {th }}$ and $w^{\text {th }}$ break point, first consider producers $i=w$ to $m$. As these producers are not yet at capacity, $\lambda_{i}=\gamma_{i}=0, \forall i=w$ to $m$.

Next, consider producers $i=1$ to $w$ - 1 . Since all these producers are at capacity $d_{i}$, a single-tier myopic analysis of (P5) will imply that the marginal value of capacity expansion $\lambda_{i}=p^{*}-v-\hat{p}^{0}$, where $p^{*}=a-b \hat{Q}$ is the optimal product price.

In preparation for calculating $\gamma_{i}$, note that when the equilibrium solution is between break points, the supplier problem (P6) reduces to $\hat{\Pi}^{o}=\underset{p^{0} \geq 0}{\operatorname{Max}}\left\{\left(p^{0}-v^{0}\right)\left(C_{w}-D_{w} p^{0}\right)\right\}$. Since this is concave in $p^{0}$, we can easily find $p^{0}$ by setting $\frac{d\left\{\left(p^{0}-v^{0}\right)\left(C_{w}-D_{w} p^{0}\right)\right\}}{d p^{0}}=0$ so that $\hat{p}^{0}=\frac{\left(C_{w}-v_{O} D_{w}\right)}{2 D_{w}}$, $\hat{Q}=C_{w}-D_{w} \hat{p}^{0}$ and $p^{*}=a-b \hat{Q}$.

Now, consider producer $i \leq w-1$. Initially, the optimal profit for this producer is $\hat{\Pi}_{i}\left(d_{i}\right)=\left(p^{*}-v-\hat{p}^{0}\right) d_{i}$. Suppose, we increase the producer capacity by $\delta$, where $\partial \rightarrow 0$, so that equilibrium is maintained and there are no fixed costs of capacity expansion. Then, if the supplier makes the additional raw material available to the producer, the optimal profit for this producer is now $\hat{\Pi}_{\mathrm{i}}\left(\mathrm{d}_{\mathrm{i}}+\partial\right)=\left(\mathrm{p}^{*}-\mathrm{v}-\hat{\mathrm{p}}^{0}+\mathrm{B}_{\mathrm{w}} \partial\right)\left(\mathrm{d}_{\mathrm{i}}+\partial\right)$.

Therefore, the marginal value of capacity expansion is $\gamma_{i}=\lim _{\partial \rightarrow 0} \frac{\hat{\Pi}_{i}(d+\partial)-\hat{\Pi}_{i}(d)}{\partial}=$ $\left(p^{*}-v-\hat{p}^{0}\right)+b \frac{(m-w+2)}{(m-w+1)}=\lambda_{i}+b \frac{(m-w+2)}{(m-w+1)}>\lambda_{i}, \forall i=1$ to $w-1$ 
Proposition 8: When the equilibrium solution lies at the $w^{\text {th }}$ break point, $\lambda_{i}=\gamma_{i}=0, \forall i=w+1$ to $m$ and $\lambda_{i}<\gamma_{i}, \forall i=1$ to $w$, where $\gamma_{i}=\lambda_{i}+b d_{i}$.

Proof. When the equilibrium solution lies at the $w^{\text {th }}$ break point, first consider producers $i=w+1$ to $m$. As these producers are not yet at capacity, $\lambda_{i}=\gamma_{i}=0, \forall i=w+1$ to $m$.

Next, consider producers $i=1$ to $\mathrm{w}$. Since all the producers are at capacity $d_{i}$, a single-tier myopic analysis of (P5) implies that the marginal value of capacity expansion would be $\lambda_{i}=p^{*}-v-\hat{p}^{0}$, where $p^{*}=a-b \hat{Q}$ is the optimal price of the producer.

To compute $\gamma_{i}$ for producers $i=1$ to $w$, first consider producer $w$. Initially, the optimal profit for this producer is $\hat{\Pi}_{w}\left(d_{w}\right)=\left(p^{*}-v-p_{w}^{o}\right) d_{w}$, where $p^{*}=a-b Q_{w}$. Suppose, we increase the producer capacity by $\partial, \partial \rightarrow 0$ so that equilibrium is maintained and there are no fixed costs of capacity expansion. Then, if the supplier makes additional raw material available to the producer, the optimal profit for this producer is $\hat{\Pi}_{\mathrm{w}}\left(\mathrm{d}_{\mathrm{w}}+\partial\right)=\left(\mathrm{p}^{*}-\mathrm{v}-\mathrm{p}_{\mathrm{w}}^{\mathrm{o}}+\mathrm{b} \partial\right)\left(\mathrm{d}_{\mathrm{w}}+\partial\right)$.

Therefore, the marginal value of capacity expansion is $\gamma_{\mathrm{w}}=\lim _{\partial \rightarrow 0} \frac{\hat{\Pi}_{\mathrm{w}}(\mathrm{d}+\partial)-\hat{\Pi}_{\mathrm{w}}(\mathrm{d})}{\partial}=$ $\left(p^{*}-v-p_{w}^{0}\right)+b d_{w}$. Using the similar logic, we can show that $\gamma_{i}=\left(p^{*}-v-p_{i}^{0}\right)+b d_{i}=\lambda_{i}+b d_{i}<\lambda_{i}, \forall i=1$ to $w$.

Proposition 9. Solving (P7) is equivalent to solving (P1) and (P2).

Proof. Observe that (P7) consists of (P2) and definitional constraints (6), (14) and (15) that represent the optimal solution of (P1) that is obtained for any value of $p^{k}$, including its optimal value. Therefore solving (P7) is equivalent to solving (P1) and (P2).

Proposition 10. Steps 1 through 4 provide an optimal solution to (P7).

Proof. Observe that for any value of raw material prices $p^{k}, \forall k$, the producer's problem is a concave optimization problem. Therefore, the Kuhn-Tucker conditions are necessary and sufficient for this problem. Since this procedure enforces the Kuhn-Tucker conditions for any value of raw material prices, including the optimal raw material prices $\widehat{p}^{k}, \forall k$, this procedure provides an optimal solution to (P7). 


\section{Construction of Imputed Demand Function $\hat{Q}\left(p^{0}\right)$ for Special case of Heterogeneous}

Capacity Across Producers

Recollect that Figure 2 represents the imputed demand function $\hat{Q}\left(p^{0}\right)$ for the special case with multiple producers producing a single product with a capacity constraint. There is heterogeneous capacity across the producers and there is a single raw material supplied by a monopolist supplier. We next explain how Figure 2 is constructed by considering what happens as raw material price $p^{0}$ changes. Without loss of generality, assume that producers are indexed in order of increasing capacity; i.e. $d_{i} \leq d_{j}$ if $i<j$. When $p^{0}>a-v$, no producer will produce a positive quantity and $Q=0$. As the price $p^{0}$ is lowered below $a-v$, by Proposition 3 and the subsequent analysis, all producers begin to produce and they will make the same production decision $q_{i}=\frac{\left(a-v-p^{0}\right)}{b(m+1)}$, so that the demand function for the raw material is $Q_{1}\left(p^{0}\right)=m q_{i}=\frac{m}{(m+1)} \frac{\left(a-v-p^{0}\right)}{b}$. The corresponding inverse demand function is $p_{1}(Q)=a-v-b \frac{(m+1)}{m} Q$. The demand function will hold until producer $i=1$ reaches its capacity limit first. That limit is reached at $p_{1}^{0}$ such that $q_{1}=\frac{\left(a-v-p_{1}^{0}\right)}{b(m+1)}=d_{1}$ or when $p_{1}^{0}=a-v-b(m+1) d_{1}$. At this price, all producers make the same quantity decision, so that the total raw material quantity is $Q_{1}=m d_{1}$. This implies that the demand function for the raw material takes the form of the linear line segment for price $p^{0}$, such that $p_{1}^{0} \leq p^{0} \leq a-v$.

As price $p^{0}$ is reduced below $p_{1}^{0}$, producer $i=1$ remains at capacity so only the remaining $(m-1)$ producers continue to increase production. So the demand function for the raw material now becomes $Q_{2}\left(p^{0}\right)=\frac{(m-1)}{m} \frac{\left(a-v-b d_{1}-p^{0}\right)}{b}$ and the corresponding inverse demand function is $p_{2}(Q)=a-v-m d_{1}-b \frac{m}{(m-1)} Q$. The demand function will hold until producer $i=2$ reaches its capacity limit, reached at $p_{2}^{0}$ such that $q_{2}=\frac{\left(a-v-b d_{1}-p_{2}^{0}\right)}{b m}=d_{2}$ or when 
$p_{2}^{0}=a-v-b d_{1}-b m d_{2}$. At this price, the total raw material quantity is $Q_{2}=d_{1}+(m-1) d_{2}$. Here again, the demand function for the raw material takes the form of the linear line segment, for prices $p^{0}$ such that $p_{2}^{0} \leq p^{0} \leq p_{1}^{0}$.

Using the same reasoning, we can show that:

$$
Q_{u}\left(p^{o}\right)=\left(\frac{m-u+1}{m-u+2}\right)\left(\frac{1}{b}\right)\left(a-v-b \sum_{i=1}^{u-1} d_{i}-p^{0}\right) \quad u=1 \text { to } m,
$$

and each line segment is defined in the range $Q_{u}<Q_{u}\left(p^{0}\right)<Q_{(u-1)}$, with break points $Q_{u}=\sum_{i=1}^{u-1} d_{i}+(m-u+1) d_{u}$ for $u=1$ to $m$ and $Q_{0}=0$. For notational compactness, we write $Q_{u}\left(p^{0}\right)=C_{u}-D_{u} p^{0}$, where $C_{u}=\left(\frac{m-u+1}{m-u+2}\right)\left(\frac{a-v-b \sum_{i=1}^{u-1} d_{i}}{b}\right)$ and $D_{u}=\left(\frac{m-u+1}{m-u+2}\right)\left(\frac{1}{b}\right)$.

Note that we will have $(m+1)$ breakpoints, so that $Q_{m} \geq d^{0}$ and $Q_{(m-1)}<d^{0}$, and that we will need to consider $m$ line segments of the demand function $Q_{u}\left(p^{0}\right)$. The demand function $\hat{Q}\left(p^{0}\right)=\min _{k=1 \text { to } m}\left\{Q_{k}\left(p^{0}\right)\right\}$ 